\title{
Performance evaluation of multi-stage reverse osmosis process with permeate and retentate recycling strategy for the removal of chlorophenol from wastewater
}

\author{
M. A. Al-Obaidi ${ }^{1}{ }^{2}$, C. Kara-Zaïtri ${ }^{1}$ and I. M. Mujtaba ${ }^{1}$ * \\ ${ }^{1}$ Chemical Engineering Division, Faculty of Engineering and Informatics. University of Bradford. \\ Bradford, West Yorkshire BD7 1DP, UK \\ 2 Middle Technical University, Iraq - Baghdad \\ *Corresponding author, Tel.: +44 01274233645 \\ E-mail address: I.M.Mujtaba@bradford.ac.uk
}

\begin{abstract}
Reverse Osmosis (RO) is one of the most widely used technologies for wastewater treatment for the removal of toxic impurities, such as phenol and phenolic compounds from industrial effluents. In this research, performance of multi-stage RO wastewater treatment system is evaluated for the removal of chlorophenol from wastewater using model-based techniques. A number of alternative configurations with recycling of permeate, retentate, and permeateretentate streams are considered. The performance is measured in terms of total recovery rate, permeate product concentration, overall chlorophenol rejection and energy consumption and the effect of a number of operating parameters on the overall performance of the alternative configurations are evaluated. The results clearly show that the permeate recycling scheme at fixed plant feed flow rate can remarkably improve the final chlorophenol concentration of the product despite a reduction in the total recovery rate.
\end{abstract}

Keywords: Spiral-wound Multi Stage Reverse Osmosis Process; Mathematical Modelling; Chlorophenol Removal, Permeate-Retentate Recycling Design.

\section{Introduction}

Phenol and phenolic compounds are considered as one of the common pollutants that can be found in effluents of several industrial processes such as, refineries, lubricant production, fertilizers, petrochemical, pharmaceutical, plastic, coal, wood, paper, pulp, and paint processes. Specifically, the phenolic compounds have high toxicity impacts at low concentrations on the whole ecosystem (Gami et al., 2014; Mohammed et al., 2016, 2017). Phenol brings intolerable tastes to drinking water at about $0.5 \mathrm{ppm}\left(3.888 \mathrm{E}-6 \mathrm{kmol} / \mathrm{m}^{3}\right.$ ) (Jiang et al., 2003). Therefore, the environmental legislated value of $0.5 \mathrm{ppm}$ of phenol has been adopted before discharging the 
effluents into sewage system. However, the European Union (EU) has regulated total phenols in drinking water to be less than 0.0005 ppm (3.888E-9 kmol/m³) (Hill and Robinson, 1975). This in turn has encouraged the employment of different abatement technologies to remove phenol from wastewater such as, steam distillation processes, organic solvent extraction, adsorption, oxidation, and membrane technology to achieve this restriction (Pinto et al., 2005; Busca et al., 2008; Mohammed et al., 2016). Among these technologies, the Reverse Osmosis RO has been recognised as an effective process in wastewater treatment applications regarding the removal of organic compounds from wastewater (Al-Obaidi et al., 2018). Also, the pilot-scale studies using single RO membrane module by Srinivasan et al. (2010, 2011); Sundaramoorthy et al.(2011a) have confirmed the feasibility of the RO process for the removal of phenol and phenolic derivatives from wastewater.

A number of previous work on stream recycling approach were made for the design of multistage RO seawater desalination process. This is a crucial scenario of conceptual design, which can probably keep the product quality and recovery ratio in case of any expected seasonal fluctuations (Sarkar et al., 2008). Al-Bastaki and Abbas (2003) studied the effect of permeate recycling on the performance of three stages seawater RO system and concluded that a recycle ratio of $25 \%$ of the product has reduced the final product concentration by $15 \%$ at the expense of $22 \%$ reduction in total water recovery. However, these results are confirmed for a design of constant feed flow rate of stage 1. Sarkar et al. (2008) studied the performance of a small scale brackish water desalination system with partial retentate recycle. The study shows that an increase in the feed temperature requires a simultaneous increase in retentate recycle to maintain a constant product rate. However, this behaviour was found to be quite different than the impact of feed salinity.

Several successful mathematical models were developed to describe the removal of phenol and phenolic compounds from wastewater using a single spiral wound RO process and focused on the impact of operating parameters on the whole performance and optimising the removal of chlorophenol using genetic algorithm (Srinivasan et al., 2009; Sundaramoorthy et al., 2011b; Srinivasan et al., 2010; Srinivasan et al., 2011; Al-Obaidi and Mujtaba, 2016; Al-Obaidi et al., 2017a; Al-Obaidi et al., 2017b; Al-Obaidi et al., 2017c). However, multi-stage RO wastewater system considering the permeate and retentate recycling scheme for the removal of phenol and phenolic compounds from wastewater has not been investigated yet. Therefore, this work 
evaluates the removal of chlorophenol removal from wastewater using a multi-stage RO network with permeate, retentate and permeate-retentate streams recycling scheme using model-based simulation. The main aim is to reduce the final chlorophenol concentration of the product to be within the strict constraints of the existence of such undesirable compounds in wastewater that affect all living organisms.

\section{Multi-stage RO Plant description}

Fig. 1 shows three proposed configurations of a pilot-scale cross-flow RO treatment system of three series stages $(n=3)$ with permeate (scenario A), retentate (scenario B) and permeateretentate (scenario $\mathrm{C}$ ) recycling scheme to remove chlorophenol from wastewater, Stage 1 contains two pressure vessels $(P V)$ connected in parallel and operating under the same conditions. Each pressure vessel holds only one spiral wound module of a commercial thin film composite membrane HM4040-LPE, Hydramem (Make: Ion Exchange, India Ltd.). The characteristics of the spiral wound module are given in Table 1, while both stages 2 and 3 contain one pressure vessel of one membrane. The permeates of all stages with relatively high quality are blended and sent as a product and the retentate of high concentration of each stage is transferred to the forward stage to processed and so on. Flow control valves (splitters) are fixed on the plant permeate and the retentate streams to adjust a portion of the recycled stream to the plant feed stream to test its impact on the overall system performance compared with normal design (no-recycle). Specifically, the product or the retentate streams will be split into different ratios and to be mixed with the plant feed in a mixer to obtain a single stream of the stage 1 . The feed flow rate, chlorophenol concentration and pressure of any splitter and mixer are represented in Eqs. (54 to 59) in Table A.2. Moreover, the stream of the first stage is pressurised by a pressure pump, which delivers the system with a maximum pressure of $20 \mathrm{~atm}$. The feed temperature was maintained at $31{ }^{\circ} \mathrm{C}$.

\section{Multi-stage RO process model}

Al-Obaidi et al. (2017d) developed a simple model for an individual spiral-wound RO system to describe the transport phenomena of permeate and solute through the membrane, which was used to simulate the removal of dimethylphenol from its aqueous solutions and shows a good agreement with experimental results over the ranges of pressure and concentration. 


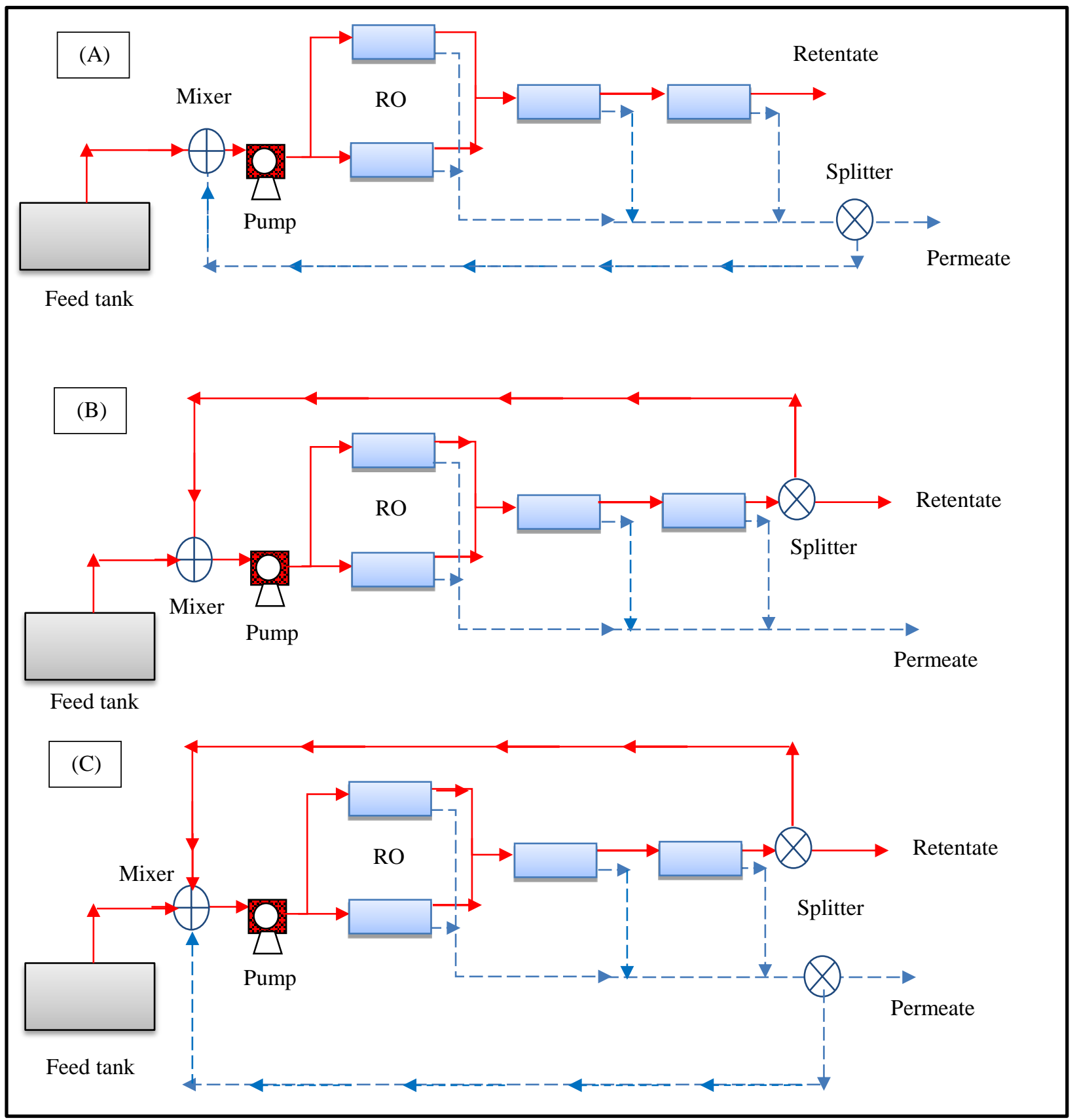

Fig. 1. Multi-stage RO process with four pressure vessels (A) permeate recycle (b) retentate recycle (C) permeate and retentate recycle 
Here, the model equations are modified to consider the removal of chlorophenol in a multi-stage RO system of different recycling approaches including; the overall mass and chlorophenol balance equations of each module, the stage and whole plant with the inlet and outlet streams. The model predicts the overall performance regarding the total product concentration, overall chlorophenol rejection, total recovery rate and energy consumption. Moreover, the model has employed (Eq. 4) in (Table A.1) derived from Sundaramoorthy et al. (2011a) to calculate the mass transfer coefficient. The details of the single spiral wound RO process and the multi-stage RO system developed model are provided in Appendix A, Table A.1 and A.2, respectively.

Table 1. Membrane characteristics and geometry (Sundaramoorthy et al., 2011a)

\begin{tabular}{|c|c|}
\hline Make & Ion Exchange, India Ltd. $^{1}$ \\
\hline Membrane material & TFC Polyamide \\
\hline Module configuration & Spiral-wound \\
\hline Feed spacer thickness $\left(t_{f}\right)$ & $0.8 \mathrm{~mm}$ \\
\hline Permeate channel thickness $\left(t_{p}\right)$ & $0.5 \mathrm{~mm}$ \\
\hline Module length $(L)$ & $0.934 m$ \\
\hline Module width $(W)$ & $8.4 \mathrm{~m}$ \\
\hline Effective membrane area (A) & $7.8456 \mathrm{~m}^{2}$ \\
\hline Module diameter & 3.25 inches \\
\hline$b$ & $8529.45\left(\frac{a t m s}{m^{4}}\right)$ \\
\hline$A_{w}{ }^{2}$ & $9.5188 \mathrm{E}-7\left(\frac{m}{a t m s}\right)$ \\
\hline$B_{s}\left(\right.$ chlorophenol) ${ }^{2}$ & $8.468 \mathrm{E}-8\left(\frac{m}{s}\right)$ \\
\hline$\varepsilon_{\text {pump }}$ & $80 \%$ \\
\hline
\end{tabular}

\section{Performance Evaluation}

The simulation of the three RO configurations shown in Fig. 1 is conducted under similar operating conditions of $6.226 \mathrm{E}-3 \mathrm{kmol} / \mathrm{m}^{3}, 5.166 \mathrm{E}-4 \mathrm{~m} / \mathrm{s}, 15$ atm and $31{ }^{\circ} \mathrm{C}$ of plant feed concentration $C_{f(\text { plant })}$, flow rate $Q_{f(\text { plant })}$, pressure $P_{f(\text { in })(\text { plant })}$ and temperature $T_{(\text {plant })}$, respectively. The selection of these parameters is based on the upper and lower guidelines of the membrane manufacturer.

\subsection{Case study 1}


In this case we assume a constant plant feed flow rate $\left(5.166 \mathrm{E}-4 \mathrm{~m}^{3} / \mathrm{s}\right)$ from the feed tank entering the mixer (Fig. 1). However, the recycled portion of the permeate or retentate will be blended to form the main feed flow rate of stage 1 . Therefore, the feed flow rate of stage 1 is continuously increased as the ratio of recycle stream increases. The new inlet feed flow rate and concentration of stage 1 for the retentate, permeate and retentate-permeate recycle scenarios are calculated using Eqs (60 to 65) in Table A.2, respectively. The simulation results of partial stream recycle of the three scenarios given in Fig. 1 can be shown in Figs. 2 and 3 considering the final chlorophenol concentration of the product, total recovery rate and energy consumption, respectively. Note that, the simulation of the process is first carried out without recycle, i.e. $(P R=0 \%)$, and then a recycle is introduced for each scenario under the same operating conditions of feed pressure, flow rate, concentration, and temperature. Also, an equal value of recycle ratio of both the retentate and permeate streams is applied for the retentate-permeate scenario.

The simulation results of Fig. 2 confirm that the permeate recycle scheme (Fig. 1A) causes a higher reduction in the final chlorophenol concentration of the product compared to other designs of retentate and permeate-retentate strategies (Fig.1 B and C, respectively). This is due to a clear reduction in the inlet feed plant concentration by recycling the low-concentration permeate stream. However, the penalty of using the conditions of case 1 of constant external plant feed flow rate is a continuous reduction in total recovery rate and an increase in energy consumption as the recovery ratio decreases (Fig. 3). This is quite valid for the three configurations shown in Fig. 1. Actually, these are expected phenomenon due to an increase in the inlet feed flow rate of all the stages, which causes an increase in feed velocity and pressure drop along each compartment (Jiang et al., 2014). This in turn will reduce the quantity of water that passed through the membrane. However, Fig. 3 shows that the permeate recycle scheme has the highest value of recovery rate and lowest value of energy consumption if compared to other recycling strategies. Note that the calculation of energy consumption is carried out based on the feed flow rate entering the pump of stage 1. 


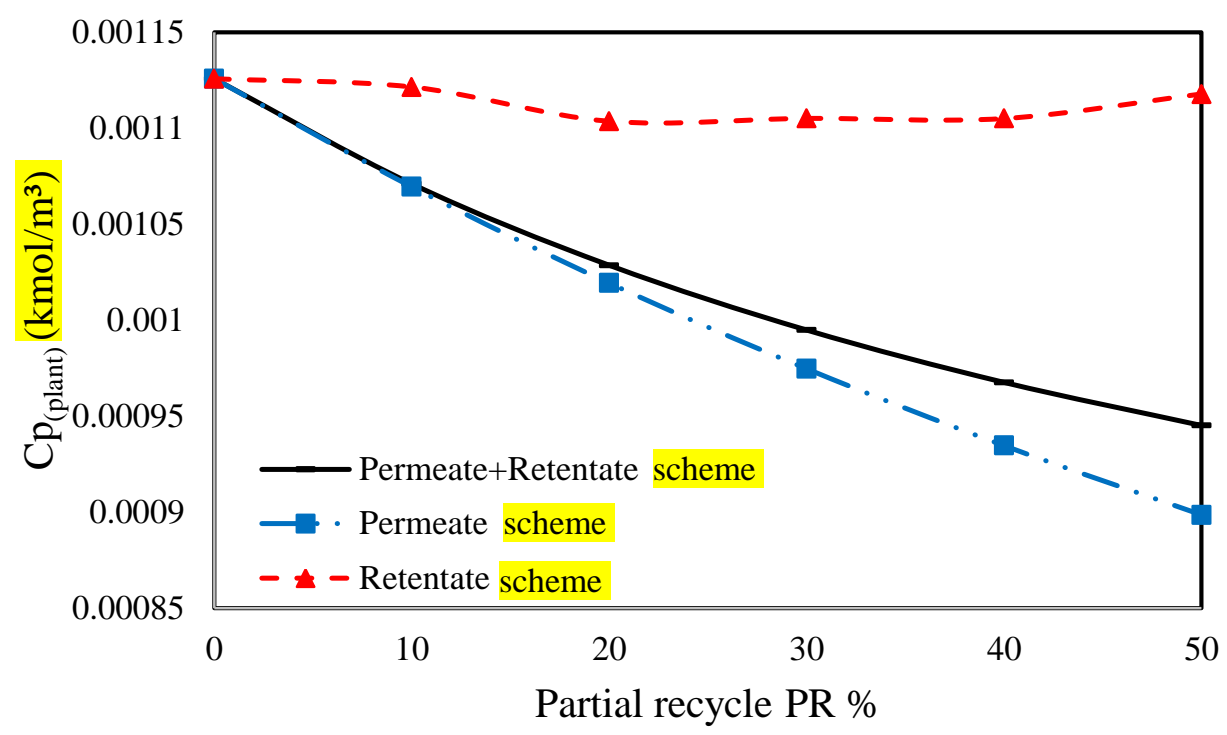

Fig. 2. The simulation results of three designs of case 1 of partial recycle on the total plant permeate concentration (plant operating conditions are: $6.226 \mathrm{E}-3 \mathrm{kmol} / \mathrm{m}^{3}, 5.166 \mathrm{E}-4 \mathrm{~m}^{3} / \mathrm{s}, 15$ atm and $31^{\circ} \mathrm{C}$ )

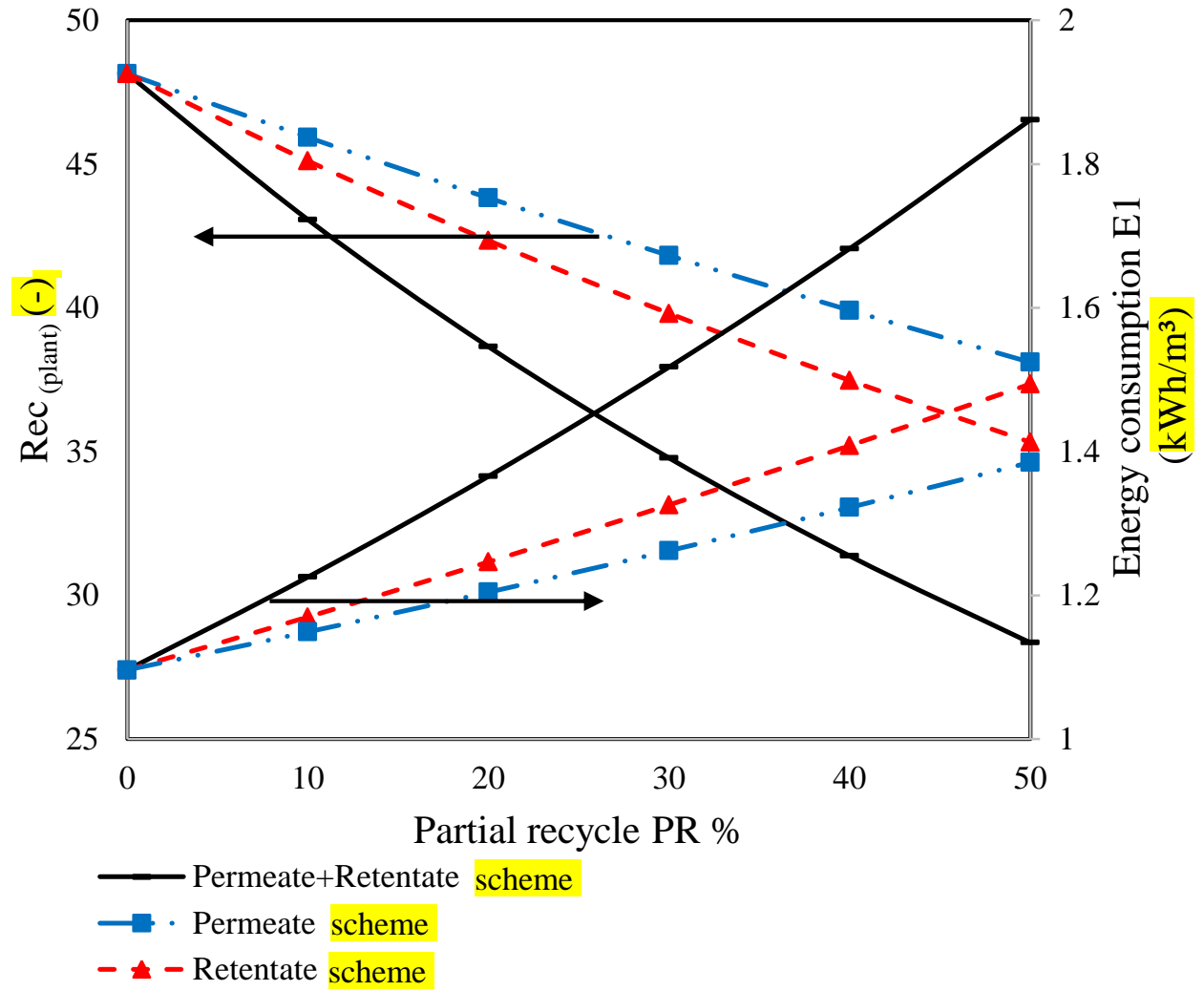

Fig. 3. The simulation results of three designs of case 1 of partial recycle on the total plant recovery and energy consumption (plant operating conditions are: $6.226 \mathrm{E}-3 \mathrm{kmol} / \mathrm{m}^{3}, 5.166 \mathrm{E}-4 \mathrm{~m} 3 / \mathrm{s}, 15 \mathrm{~atm}$ and $31^{\circ} \mathrm{C}$ ) 


\subsection{Case study 2}

In this case study we assume a variable external plant feed flow rate which will ensure a constant feed flow rate at the stage 1 for both permeate recycle scheme (Fig. 1A) and retentate recycle scheme (Fig. 1B). Consequently, the external plant feed flow rate will decline as the ratio of recycle increases to keep a constant feed flow rate at stage 1 of $5.166 \mathrm{E}-4 \mathrm{~m}^{3} / \mathrm{s}$ and therefore the feed concentration of stage 1 will vary. However, the operating parameters of the plant feed pressure, concentration and temperature will remain constant. The simulation results of this case in terms of the total product concentration, total recovery rate and energy consumption are shown in Figs. 4 and 5, respectively. Note, the retentate-permeate scheme has been exempted in case 2 due to its unsatisfied performance based on the final chlorophenol concentration of the product, total recovery rate and energy consumption.

Fig. 4 shows a continuous reduction of total water recovery as a result to increasing the retentate recycle portion for case 2 . This scheme ensures an increase in inlet feed concentration of stage 1 as a result to increasing retentate recycle ratio which corresponding to a variable external feed flow rate. This in turn causes higher feed concentration that increases the concentration polarisation of all the stages and reduces the recovery, which causes an increase of the energy consumption (Fig. 4). Specifically, increasing the feed concentration leads to increase the bulk concentration, which causes an increase in the product concentration (Fig. 5). In this respect, the simulation results of Fig. 4 show that the use of case 2 introduces an increase in the total recovery rate for scenario A (Fig. 1) as the recycled ratio of the permeate increases compared to the previous results of case 1 shown in Fig. 3. This behaviour can be attributed to the use of constant inlet feed flow rate of the first stage. This scheme ensures a reduction of inlet feed concentration of stage 1, leading to reduced concentration polarisation impact and increased water flux through the membrane. Therefore, the final chlorophenol concentration of the product has decreased as the recycled ratio of permeate stream increases (Fig. 5). Indeed, the RO process requires a considerable amount of energy as a result to using high pressure pump (Gu et al., 2017). Interestingly, the simulation result of the permeate recycling scheme of case 2 has approved its strength to reduce energy required for wastewater treatment. 


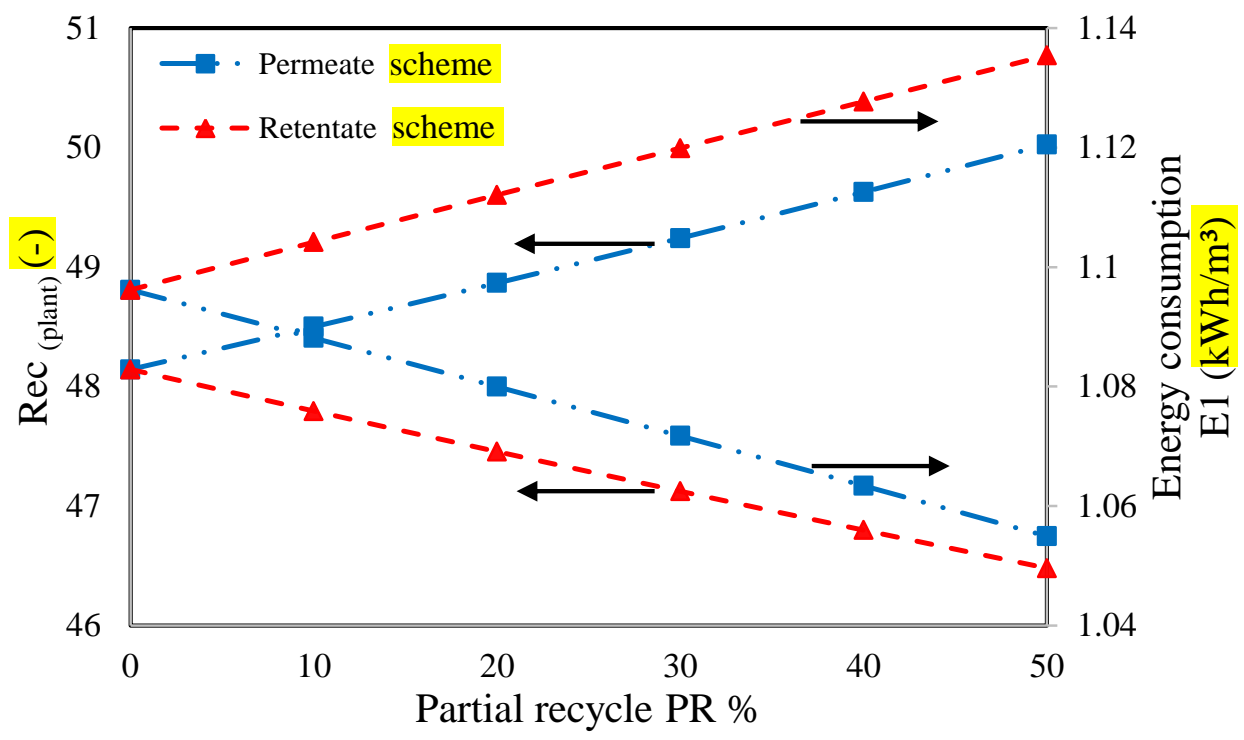

Fig. 4. The simulation results of two designs of case 2 of partial recycle on the total plant recovery and energy consumption (plant operating parameters are: $6.226 \mathrm{E}-3 \mathrm{kmol} / \mathrm{m}^{3}, 15 \mathrm{~atm}, 31^{\circ} \mathrm{C}$ and variable feed flow rate)

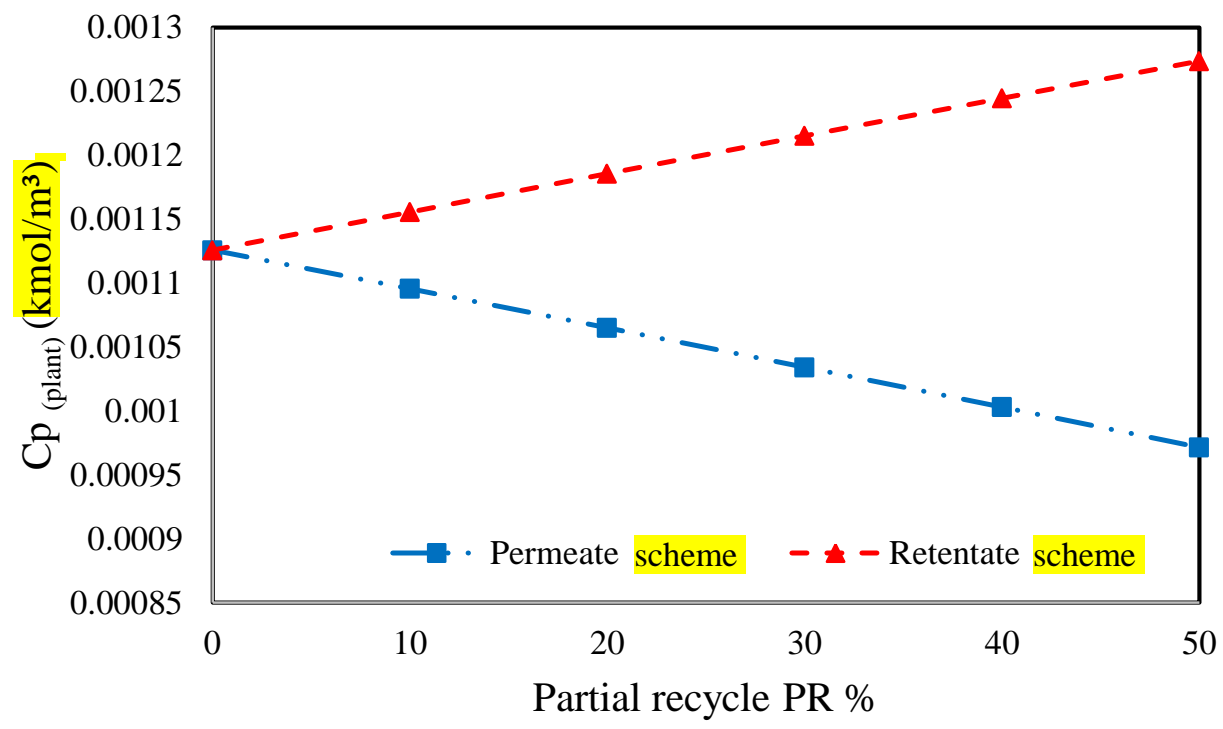

Fig. 5. The simulation results of two strategies of case 2 of partial recycle on the total plant permeate concentration (plant operating parameters are: $6.226 \mathrm{E}-3 \mathrm{kmol} / \mathrm{m}^{3}, 15 \mathrm{~atm}, 31^{\circ} \mathrm{C}$ and variable feed flow rate)

Considering the results of cases 1 and 2, it can be concluded that the permeate recycling scheme has considerable impact on the overall performance of the plant compared to the retentate recycling strategy. Therefore, the permeate recycle scheme of cases 1 and 2 has been chosen in the next section to investigate the effect of the operating parameters of feed temperature, pressure, and concentration on the overall performance of the system. 


\section{The effect of operating parameters on the performance of the process}

The design of permeate recycle with a portion varies from 0 to $50 \%$ is selected here to analyse the impact of operating parameters on the whole performance of the system.

\subsection{The effect of feed temperature}

The dependency of solvent $A_{w}$ and solute $B_{s}$ permeability constants on the feed temperature is given in Eqs. (30) and (31) of Table A.1, respectively. Here, the reference temperature $T_{\text {ref }}$ of 31 ${ }^{\circ} \mathrm{C}$, which used in the experiments of Sundaramoorthy et al. (2011a), will be considered to estimate the constants at different operating temperatures.

The impact of a variation of $27-40{ }^{\circ} \mathrm{C}$ of operating plant temperature $T_{\text {(plant) }}$ versus a range of $0-50 \%$ permeate recycle ratio of cases 1 and 2 on the total recovery rate and chlorophenol rejection are shown in Figs. A.1 and A.2 of Appendix A, respectively. Table 2 shows the final chlorophenol concentration of the product, recovery rate, energy consumption and rejection parameter for with and without permeate recycle of cases 1 and 2. Here, it is assumed that the simulation results at 27 and $40{ }^{\circ} \mathrm{C}$ are as the base case, which are used later to calculate the improvement (+,-) of cases 1 and 2 (Table 2). Basically, the improvement (+,-) percentage calculation is achieved by comparing of the new values calculated after changing the temperature, pressure, and feed concentration from the base case to the new value. Positive values mean an increase with respect to the base case study and the negative values a decrease. The improvement $(+,-)$ has been calculated in terms the permeate concentration, recovery, rejection, and energy consumption. It is not difficult to see that an increase in the operating temperature causes an increase in the recovery rate and chlorophenol rejection for the two scenarios of with and without permeate recycle and for the two cases 1 (Constant External Plant Feed Flow rate) and 2 (Constant Stage 1 Feed Flow rate) (Figs. A.1 and A.2 of Appendix A). This can be explained by dilatating of membrane pores as a result to increase the temperature, which aids higher water flux through the membrane and dilutes the permeate concentration at the permeate channel. However, the existences of $50 \%$ permeate recycle in case 1 has reduced the total recovery rate by about 17 and $28.7 \%$ at 27 and $40{ }^{\circ} \mathrm{C}$, respectively compared to without recycle mode. In contrast, a permeate recycle of $50 \%$ of case 1 causes a small increase in the chlorophenol rejection by about 1.22 and $1.15 \%$ at 27 and $40{ }^{\circ} \mathrm{C}$, respectively compared to $0 \%$ 
permeate recycle mode. This is compared to the simulation results of case 2 , which show an inverse action of a small increase in recovery rate by about 3.49 and $4.32 \%$ at 27 and $40{ }^{\circ} \mathrm{C}$, respectively and a small decrease in chlorophenol rejection by about 1.93 and $1.14 \%$ at 27 and $40{ }^{\circ} \mathrm{C}$, respectively compared to without permeate recycle. Having said this, the permeate recycle of case 2 has improved its robustness as it keeps the recovery rate without any reduction compared to case 1 .

Fig 6 shows the impact of feed temperature variation of $27-40{ }^{\circ} \mathrm{C}$ versus the permeate partial recycle ratio on the performance of cases 1 and 2 regarding the final chlorophenol concentration of the product. Interestingly, Fig. 6 confirms that case 1 has always a higher reduction of chlorophenol concentration at any temperature compared to case 2. Also, an increase in feed temperature can reinforce this reduction. Moreover, Table 2 shows that a $50 \%$ permeate recycle of case 1 can improve the total permeate concentration by about 15.3 and $31.1 \%$ at 27 and 40 ${ }^{\circ} \mathrm{C}$, respectively compared to without recycle mode. Also, a $50 \%$ permeate recycle of case 2 has gained 9.89 and $22.98 \%$ at 27 and $40{ }^{\circ} \mathrm{C}$, respectively compared to without recycle mode. Fig. A.3 of Appendix A shows a comparative analysis of the simulation results of energy consumption for cases 1 and 2 as a result to the same variation of operating temperature and permeate recycle ratio. It can be observed that case 1 of constant plant feed flow rate consumes more energy compared to case 2 of constant stage 1 feed flow rate. Specifically, a $50 \%$ permeate recycle of case 1 increases energy consumption by about 21.05 and 39.74 at 27 and $40{ }^{\circ} \mathrm{C}$, respectively compared to no recycle mode. On the other hand, a $50 \%$ permeate recycle of case 2 has a small positive impact of about 3.0 and $3.84 \%$ at 27 and $40{ }^{\circ} \mathrm{C}$, respectively compared to no recycle mode. The interesting finding is that the energy consumption is continuously reduced for case 2 as the ratio of permeate recycle or the feed temperature increases. This can be attributed to a continuous increasing of the total recovery rate with the feed temperature, which already reduces the energy consumption as can be seen in Eq. (29) in Table A.1. 


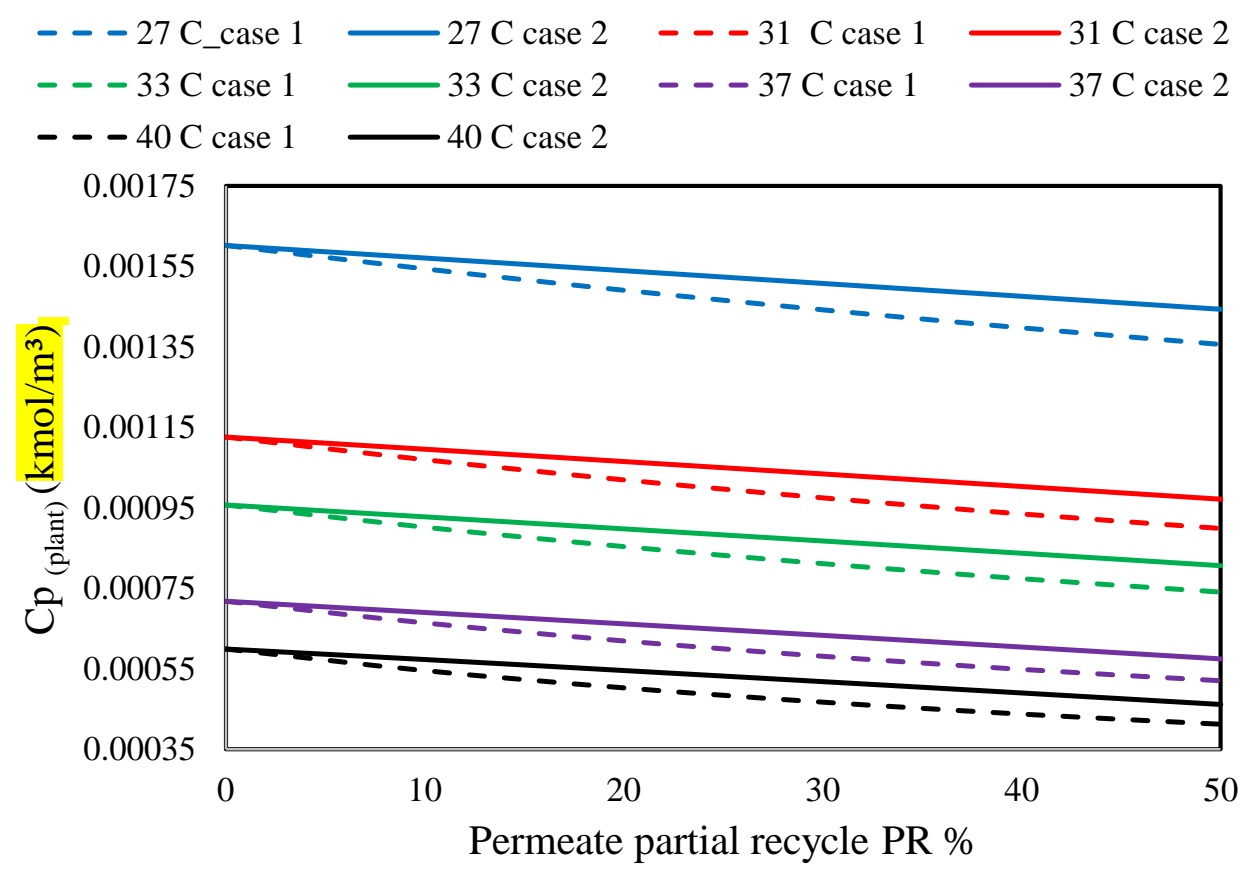

Fig. 6. The impact of plant feed temperature on the total plant product concentration of permeate recycle scheme of cases 1 and 2 (plant operating conditions of case 1: $6.226 \mathrm{E}-3 \mathrm{kmol} / \mathrm{m}^{3}, 5.166 \mathrm{E}-4 \mathrm{~m} / \mathrm{s}, 15$ atm and variable plant feed temperature and plant operating parameters of case $2: 6.226 \mathrm{E}-3 \mathrm{kmol} / \mathrm{m}^{3}, 15$ atm and variable plant feed flow rate and temperature)

\subsection{The effect of feed pressure}

Figs. A.4 and A.5 of Appendix A show the impact of plant feed pressure $P_{f(i n)(p l a n t)}$ variation of $13-20$ atm versus the permeate recycle ratio of $0-50 \%$ of cases 1 and 2 on the overall plant performance of total recovery rate and chlorophenol rejection, respectively. Here, it is assumed that the simulation results at 13 and 20 atm are as the base case, which are used later to calculate the improvement (+,-) of cases 1 and 2. Therefore, Table 2 illustrates the improvement (+,-) percentage calculations of with and without $50 \%$ permeate recycle of cases 1 and 2 considering the plant performance include the permeate concentration, total rejection, recovery, and energy consumption.

It is easy to notice that an increase in plant feed pressure has a small positive impact on total recovery rate for case 2 compared to a dramatic reduction in case 1 (Figs. A.4 and A.5 of Appendix A). Also, Table 2 affirms that a $50 \%$ permeate recycle causes a reduction of total recovery rate by about 19.19 and $22.79 \%$ for case 1and an increase of total recovery rate by about 3.29 and $5.13 \%$ for case 2 as a response of a step change in feed pressure from 13 to 20 atm, respectively. These results are in line with the simulation results of feed temperature step 
change. Specifically, the implementing of $50 \%$ permeate recycle of case 1 enhances the chlorophenol rejection by only about 0.65 and $2.83 \%$ compared to no permeate recycle at 13 and 20 atm, respectively. This in comparison to case 2, which causes a decrease of chlorophenol rejection by about 1.15 and $3.4 \%$ compared to no permeate recycle at 13 and 20 atm, respectively. Therefore, it can be said that the chlorophenol rejection has not remarkably changed after considering the permeate recycle mode of cases 1 and 2.

Figs. A.4 and A.5 of Appendix A show a common behaviour of a small decrease in chlorophenol rejection as the pressure increases except the case of $50 \%$ permeate recycle of case 1 . Generally, the impact of increasing operating pressure on chlorophenol rejection can be explained in two different ways. Firstly, an increase of pressure increases the water flux, which reduces the permeate concentration and increases the rejection. Secondly, an increase in chlorophenol concentration at the membrane wall is associated with an increase in pressure, which increases the solute flux and reduces chlorophenol rejection. Therefore, there is a number of parameters that control the rejection of compounds especially for the case of permeate recycle mode, where the inlet feed concentration varies with the ratio of permeate recycle. Interestingly, Figs. A.4 and A.5 of Appendix A approximately show an optimum value of pressure that can achieve higher rejection. However, this value depends on whether if there is a permeate recycle or not. On the other hand, it is believed that the final chlorophenol concentration of the product can extensively picture the performance of the process and consider as the main indicator of the process efficiency especially after considering the permeate recycle mode.

Figs. 7 and A.6 (Appendix A) show the impact of same feed pressure variation on the final chlorophenol concentration of the product and energy consumption, respectively with $50 \%$ permeate recycle in cases 1 and 2. Fig. 7 shows that an increase of operating pressure from 13 to $20 \mathrm{~atm}$ has a fluctuated impact on the product concentration (reduced and increased). This might be attributed to the variation of water solute fluxes through the membrane caused by the pressure change. Also, Fig. 7 shows a clear reduction of chlorophenol concentration using a permeate recycle scheme of case 1 compared to case 2 . Also, an increase in the permeate recycle ratio can improve this reduction. Moreover, increasing the operating pressure to $20 \mathrm{~atm}$ and after $30 \%$ permeate recycle can promote the system performance of case 1 and aids to achieve the lowest chlorophenol concentration. Specifically, a $50 \%$ permeate recycle scheme of case 1 at operating pressure of $20 \mathrm{~atm}$ can lower the chlorophenol concentration by a ratio of $30 \%$ based on no 
recycle design. Therefore, the analysis of feed pressure step change confirms that case 1 is more favorable to achieve higher efficiency of the final chlorophenol concentration of the product if compared to case 2. However, the main drawback of using this procedure is the reduction of total recovery as the permeate recycle ratio increases, which ultimately increases the requirements of more energy consumption (Fig. A.6 of Appendix A). Moreover, the consumption of energy at higher pressures is more convenient than lower pressures for both cases 1 and 2.

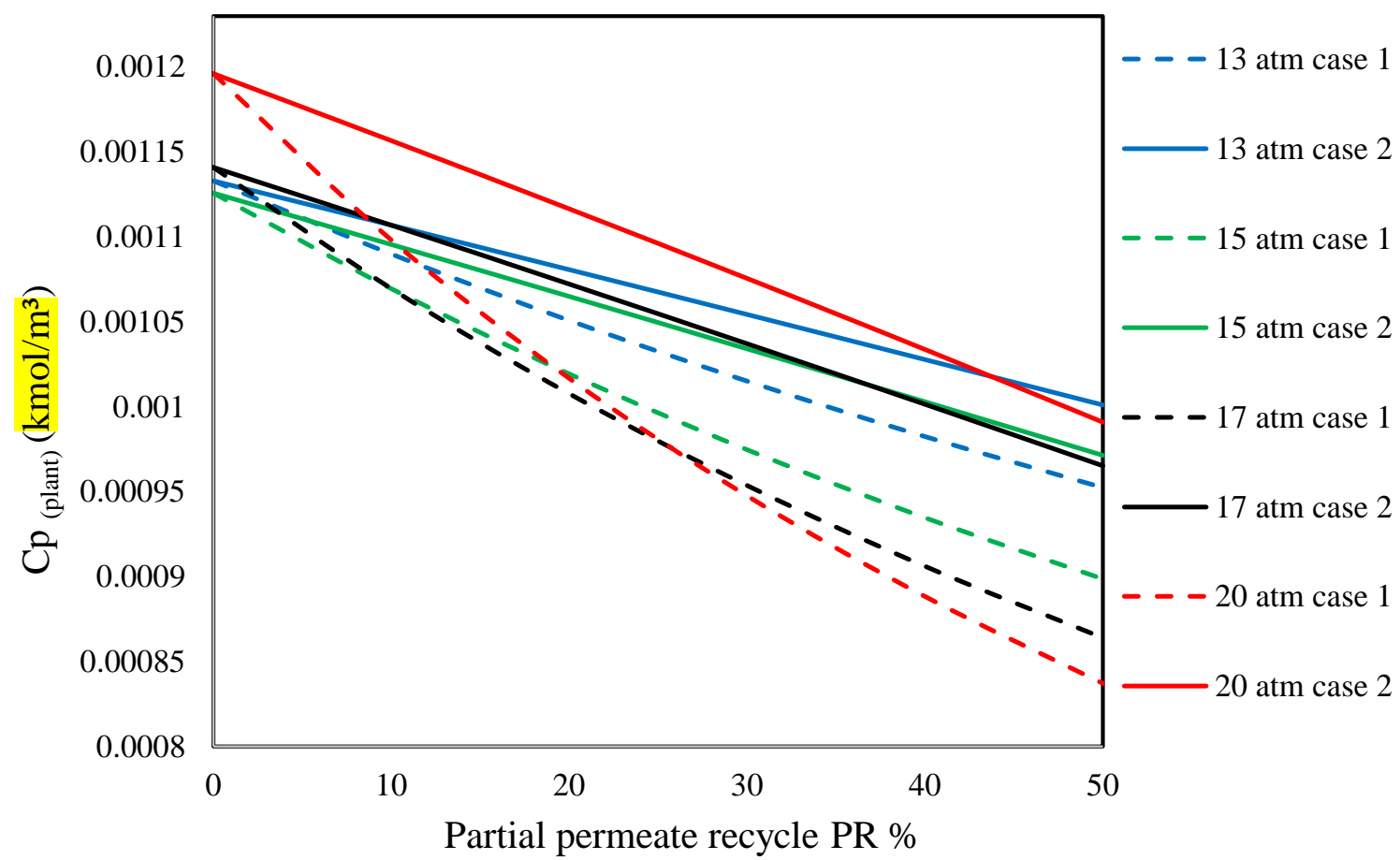

Fig. 7. The impact of plant feed pressure on the total plant product concentration of permeate recycle scheme of cases 1 and 2 (plant operating conditions of case 1: 6.226E-3 kmol $/ \mathrm{m}^{3}, 5.166 \mathrm{E}-4 \mathrm{~m}^{3} / \mathrm{s}, 31^{\circ} \mathrm{C}$ and variable feed pressure and plant operating parameters of case 2: 6.226E-3 kmol/m $\mathrm{m}^{3}$ and $31{ }^{\circ} \mathrm{C}$ and constant stage 1 feed flow rate and pressure)

\subsection{The effect of external plant feed concentration}

Figs. A.7 and A.8 of Appendix A show the impact of external plant feed concentration $C_{f(p l a n t)}$ variation of $6.226 \mathrm{E}-3-9.5 \mathrm{E}-3 \mathrm{kmol} / \mathrm{m}^{3}$ versus the permeate recycle ratio of $0-50 \%$ of cases 1 and 2 on the total recovery rate and chlorophenol rejection, respectively. Also, Table 2 shows the advantages and disadvantages of using a $50 \%$ permeate recycle of cases 1 and 2 compared to no recycle mode. Here, it is assumed that the simulation results at $6.226 \mathrm{E}-3$ and $9.5 \mathrm{E}-3 \mathrm{kmol} / \mathrm{m}^{3}$ are as the base case, which are used later to calculate the improvement (+,-) of cases 1 and 2. Figs 
A.7 and A.8 of Appendix A illustrate a noticeable reduction of total recovery rate and slightly increase in chlorophenol rejection due to an increase in the external feed concentration. Specifically, an increase of plant feed concentration from $6.226 \mathrm{E}-3$ to $9.5 \mathrm{E}-3 \mathrm{kmol} / \mathrm{m}^{3}$ causes a reduction of recovery rate of $8.49,5.57$ and $7.81 \%$ for no permeate recycle and $50 \%$ permeate recycle of case 1 and 2, respectively. Simultaneously, this step change of feed concentration causes an increase of chlorophenol rejection of about 2.66, 2.3 and $3 \%$ of no permeate recycle and $50 \%$ permeate recycle of case 1 and 2, respectively. The reason behind this phenomenon is that an increase in feed concentration causes an increase in the osmotic pressure and pressure drop, which reduces the driving force of water flux through the membrane and reduces the recovery rate. This in turn increases the concentration polarisation impact, which increases the solute flux and ultimately increases the concentration of chlorophenol in the permeate channel. Therefore, the final chlorophenol concentration of the product increases as a result to an increase in feed concentration as can be shown in Fig. 8. In contrast, the overall chlorophenol rejection increases in spite of increasing the final chlorophenol concentration of the product as can be shown in Fig. A.7 and A.8 of Appendix A as a result to an increase in the feed concentration. This phenomenon is based on the fact that an increase of feed concentration can cause an increase in the concentration polarization, but the increase of permeate concentration is still incomparable with the increase of feed concentration in the feed compartment. Therefore, the chlorophenol rejection increases due to an increase in the feed concentration according to Eq. (42) in Table A.2 of Appendix A. These results are same as to what observed by Gómez et al. (2009), who tested three types of membranes.

Table 2 shows that the existences of $50 \%$ permeate recycle of case 1 can widely improve the final chlorophenol concentration of the product by about 20 and $18 \%$ based on base cases of feed concentration of $6.226 \mathrm{E}-3$ and $9.5 \mathrm{E}-3 \mathrm{kmol} / \mathrm{m}^{3}$, respectively. However, a $50 \%$ permeate recycle of case 2 has a lower ability to reduce the chlorophenol concentration by about $13.7 \%$ and $13.4 \%$ based on base cases of feed concentration of $6.226 \mathrm{E}-3$ and $9.5 \mathrm{E}-3 \mathrm{kmol} / \mathrm{m}^{3}$, respectively. Moreover, the issue of case 1 of lowering the recovery rate and increasing the demand of energy consumption (Fig. A.9 of Appendix A) is still valid based on no recycle mode as can be seen in Table 2 . 


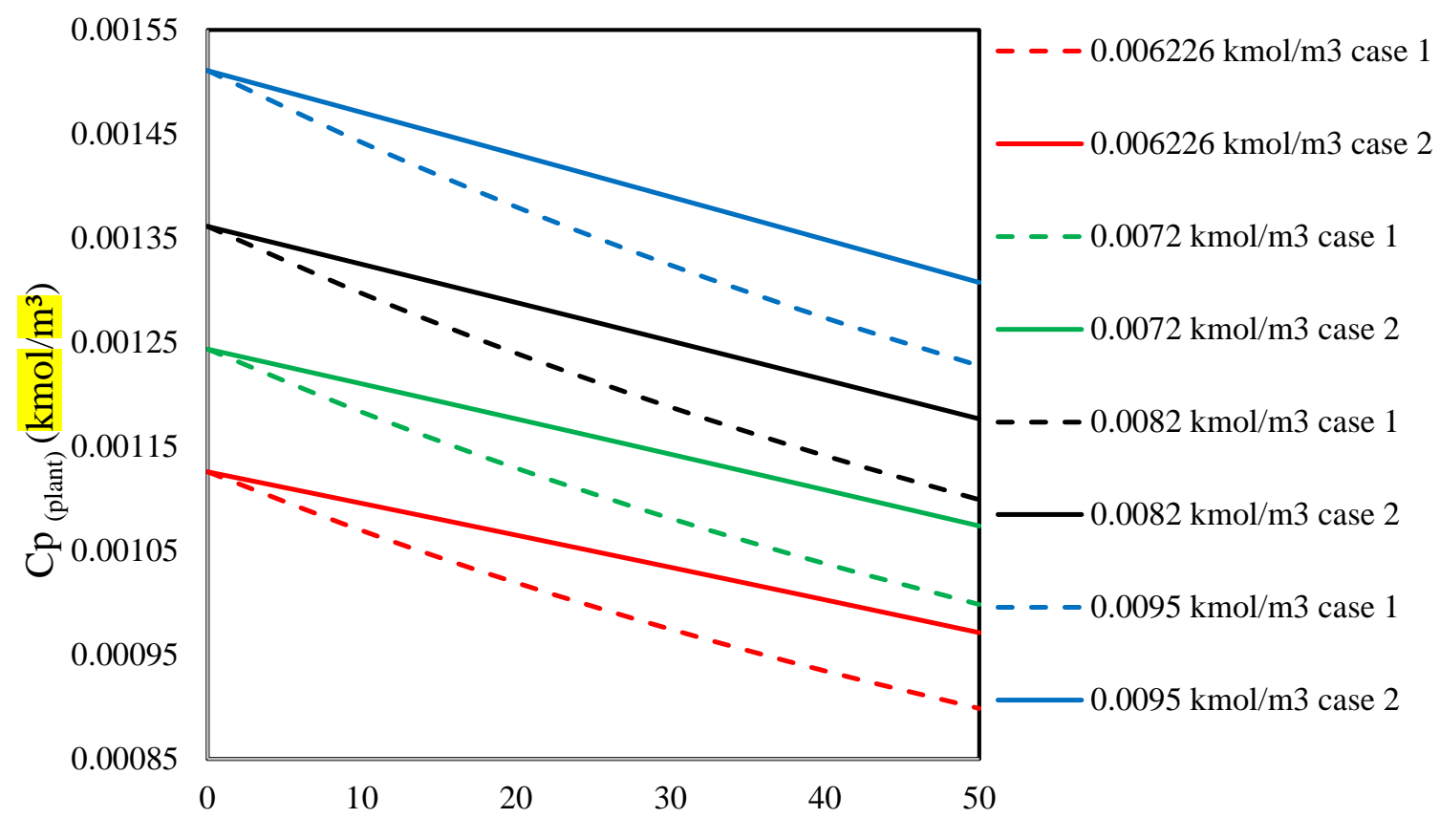

Partial permeate recycle PR \%

Fig. 8. The impact of feed plant concentration on the total plant product concentration of permeate recycle design of cases 1 and 2 (plant operating conditions of case 1: $15 \mathrm{~atm}, 5.166 \mathrm{E}-4 \mathrm{~m} / \mathrm{s}, 31^{\circ} \mathrm{C}$ and variable feed concentration and plant operating parameters of case $2: 15 \mathrm{~atm}, 31^{\circ} \mathrm{C}$ and variable plant feed flow rate and concentration)

To summaries, the variation of operating parameters of plant feed temperature, pressure, and concentration has different views regarding the process performance indicators of total recovery rate, chlorophenol concentration, energy consumption and the final chlorophenol concentration of the product. Having said this, case 1 of $50 \%$ permeate recycle has its own advantages of lowering the product concentration despite a noticeable reduction in total recovery rate and higher requirements of energy consumption. On the other hand, $50 \%$ permeate recycle of case 2 has kept the total recovery and energy consumption in a similar level of no permeate recycle mode and gained lower efficiency in reducing of product concentration compared to case 1 . Therefore, this study has illustrated two different criteria of permeate recycle (cases 1 and 2) and the decision of selecting the proper method is quite depend on the main objective of the process treatment. Also, the optimisation of the process is a crucial, which can estimate the best operating conditions that secure the allocation of the highest performance. 
Table 2. The simulation results of operating parameters variation on the plant performance of cases 1 and 2 of permeate recycle design

\begin{tabular}{|c|c|c|c|c|c|c|c|c|c|c|c|}
\hline \multirow[b]{2}{*}{$\begin{array}{c}\text { Tested } \\
\text { operating } \\
\text { parameter }\end{array}$} & \multirow[b]{2}{*}{$\begin{array}{l}0 \\
\tilde{U} \\
\tilde{U}\end{array}$} & \multirow[b]{2}{*}{ 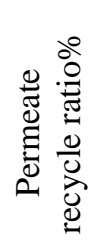 } & \multicolumn{9}{|c|}{ Tested variables } \\
\hline & & & 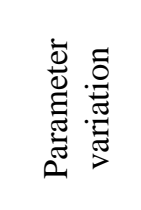 & 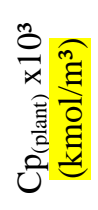 & 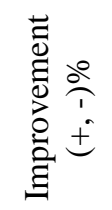 & 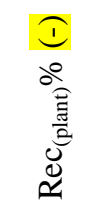 & 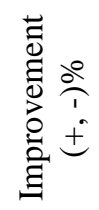 & 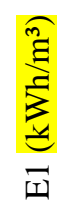 & 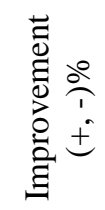 & 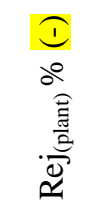 & 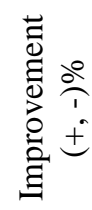 \\
\hline \multirow{6}{*}{$\begin{array}{l}\text { Temp. } \\
(27-40 \\
\left.{ }^{\circ} \mathrm{C}\right)\end{array}$} & Base & 0 & 27 & 1.60 & -- & 39.50 & -- & 1.33 & -- & 74.27 & -- \\
\hline & 1 & 50 & 27 & 1.36 & +15.3 & 32.73 & -17.13 & 1.61 & -21.05 & 75.18 & +1.22 \\
\hline & 2 & 50 & 27 & 1.44 & +9.89 & 40.88 & +3.49 & 1.29 & +3.00 & 72.83 & -1.93 \\
\hline & Base & 0 & 40 & 0.599 & -- & 67.41 & -- & 0.78 & -- & 90.37 & -- \\
\hline & 1 & 50 & 40 & 0.412 & +31.18 & 48.05 & -28.71 & 1.09 & -39.74 & 91.42 & +1.15 \\
\hline & 2 & 50 & 40 & 0.461 & +22.98 & 70.33 & +4.32 & 0.75 & +3.84 & 89.34 & -1.14 \\
\hline \multirow{6}{*}{$\begin{array}{c}\text { Pressure } \\
(13-20 \\
\text { atm })\end{array}$} & Base & 0 & 13 & 1.132 & -- & 39.17 & -- & 1.16 & -- & 81.80 & -- \\
\hline & 1 & 50 & 13 & 0.952 & +15.93 & 31.65 & -19.19 & 1.44 & -23.75 & 82.33 & +0.65 \\
\hline & 2 & 50 & 13 & 1.00 & +11.64 & 40.46 & +3.29 & 1.13 & +3.18 & 80.85 & -1.15 \\
\hline & Base & 0 & 20 & 1.196 & -- & 68.14 & -- & 1.03 & -- & 80.78 & -- \\
\hline & 1 & 50 & 20 & 0.837 & +30.01 & 52.61 & -22.79 & 1.33 & -29.53 & 83.08 & +2.83 \\
\hline & 2 & 50 & 20 & 0.991 & +17.15 & 71.65 & +5.13 & 0.98 & +4.88 & 78.03 & -3.40 \\
\hline \multirow{6}{*}{$\begin{array}{c}\text { Conc. } \\
(6.226 \mathrm{E}-3 \\
-9.5 \mathrm{E}-3 \\
\left.\mathrm{kmol} / \mathrm{m}^{3}\right)\end{array}$} & Base & 0 & $6.226 \mathrm{E}-3$ & 1.125 & -- & 48.14 & -- & 1.09 & -- & 81.91 & -- \\
\hline & 1 & 50 & $6.226 \mathrm{E}-3$ & 0.899 & +20.17 & 38.10 & -20.85 & 1.38 & -26.34 & 82.83 & +1.12 \\
\hline & 2 & 50 & $6.226 \mathrm{E}-3$ & 0.971 & +13.71 & 50.02 & +3.90 & 1.05 & +3.76 & 80.56 & -1.65 \\
\hline & Base & 0 & $9.5 \mathrm{E}-3$ & 1.510 & -- & 44.05 & -- & 1.19 & -- & 84.09 & -- \\
\hline & 1 & 50 & $9.5 \mathrm{E}-3$ & 1.227 & +18.75 & 35.98 & -18.32 & 1.46 & -22.43 & 84.76 & +0.79 \\
\hline & 2 & 50 & $9.5 \mathrm{E}-3$ & 1.307 & +13.46 & 46.11 & +4.67 & 1.14 & +4.46 & 83.10 & -1.17 \\
\hline
\end{tabular}

The simulation results of Table 2 indicate that the best chlorophenol product concentration reduction can be achieved at implementing of high temperature, high pressure, and low feed concentration in both $50 \%$ permeate recycle of cases 1 and 2. Also, Table 2 shows that the highest reduction of the final chlorophenol concentration of the product is carried out by using case 1 of $50 \%$ permeate recycle at $40{ }^{\circ} \mathrm{C}$.

The next section highlights the study of variable external feed flow rate and its impact on the process performance.

\subsection{The effect of external plant feed flow rate}

The case study 2 of variable external plant feed flow rate has not captured the effect of increasing the external plant feed flow rate in the overall RO performance. This is due to the importance of lowering external plant feed flow rate from the base case of $5.166 \mathrm{E}-4 \mathrm{~m}^{3} / \mathrm{s}$ to a certain value that appropriate to produce a fixed feed flow rate at stage 1 after being combined 
with the recycled stream of ascended recycled ratio. Therefore, the authors believe that there is a necessity to explore the impact of variable external feed flow rate with both positive and negative directions on the process performance (higher and lower than $5.166 \mathrm{E}-4 \mathrm{~m}^{3} / \mathrm{s}$ ). The selected values of external plant feed flow rate are $3.5 \mathrm{E}-4$ and $7 \mathrm{E}-4 \mathrm{~m}^{3} / \mathrm{s}$ at fixed operating pressure, concentration, and temperature.

Figs. A.10 and A.11 of Appendix A show the impact of plant feed flow rate $Q_{f(p l a n t)}$ variation of $3.5 \mathrm{E}-4-7 \mathrm{E}-4 \mathrm{~m} / \mathrm{s}$ versus the permeate recycle ratio of $0-50 \%$ of cases 1 and 2 on the total recovery rate and chlorophenol rejection, respectively. Also, Table 3 shows the advantages and disadvantages of using a $50 \%$ permeate recycle of cases 1 and 2 compared to no recycle mode. Here, it is assumed that the simulation results at $3.5 \mathrm{E}-4$ and $7 \mathrm{E}-4 \mathrm{~m}^{3} / \mathrm{s}$ are as the base case, which are used later to calculate the improvement $(+,-)$ of cases 1 and 2. Clearly, the feed flow rate has a passive effect on the recovery rate and positive impact on chlorophenol rejection compared to the case of feed temperature and pressure shown in Sections 5.1 and 5.2, respectively. Moreover, Figs. A.10 and A.11 of Appendix A indicate that a step change in the plant feed flow rate from $3.5 \mathrm{E}-4$ to $7 \mathrm{E}-4 \mathrm{~m} 3 / \mathrm{s}$ causes a remarkable increase in chlorophenol rejection of about $10.18 \%$, $5.87 \%$ and $13.93 \%$ for $0 \%$ permeate recycle mode and $50 \%$ permeate recycle of cases 1 and 2 , respectively. However, this has been accompanied by a reduction in total recovery rate by about $53 \%, 51.4 \%$ and $54.6 \%$ of $0 \%$ permeate recycle mode and $50 \%$ permeate recycle of cases 1 and 2, respectively. This might be attributed to an increase of turbulence inside the module as a result to an increase in feed flow rate, which reduces the concentration polarisation and increases the rejection parameter. However, increasing the feed flow rate is associated with higher velocity and lower residence time inside the module. This in turn will reduce the quantity of water passes through the membrane and ultimately reduces the recovery rate. The same findings have been confirmed by Lee et al. (2010) and Al-Obaidi and Mujtaba (2016). Consequently, the energy consumption increases as a result to an increase in the feed flow rate as can be shown in Fig. A.12 of Appendix A.

Fig. 9 shows the impact of a variation of plant feed flow rate of $3.5 \mathrm{E}-4-7 \mathrm{E}-4 \mathrm{~m} 3 / \mathrm{s}$ versus a variation of $0-50 \%$ permeate recycle ratio of cases 1 and 2 on the final chlorophenol concentration of the product. It is clearly noticed that an increase in feed flow rate enhances the reduction of product chlorophenol concentration and also a permeate recycle design of case 1 has a higher reduction of chlorophenol product concentration compared to case 2. However, the 
progress of this reduction is continuously reduced as the feed flow rate increases. This fact is addressed in Table 3 where the $50 \%$ permeate recycle of case 1 has a positive reduction of the final chlorophenol concentration of the product of about $30 \%$ and $12.66 \%$ at $3.5 \mathrm{E}-4$ and $7 \mathrm{E}-4$ $\mathrm{m}^{3} / \mathrm{s}$, respectively compared to a base case of no recycle mode. However, a $50 \%$ permeate recycle of case 2 has achieved lower reduction in chlorophenol product concentration of $17 \%$ and $10 \%$ at $3.5 \mathrm{E}-4$ and $7 \mathrm{E}-4 \mathrm{~m} / \mathrm{s}$, respectively compared to $0 \%$ permeate recycle mode. Moreover, Table 3 confirms the same fact that a $50 \%$ permeate recycle of case 1 has a negative correlation with the total recovery rate and energy consumption based on no recycle mode compared to case 2 . Also, the design of $50 \%$ permeate recycle of cases 1 and 2 has a small impact on the overall chlorophenol rejection.

To summarise, the simulation results of Table 3 indicate that running the process at low feed flow rate in $50 \%$ permeate recycle of case 1 would highly improve the final chlorophenol concentration of the product based on no recycle mode and compared to case 2. However, increasing feed flow rate to $7 \mathrm{E}-4 \mathrm{~m} / \mathrm{s}$ would excessively improve the product chlorophenol concentration to be lower than the one attained at the lowest feed flow rate of 3.5E-4.

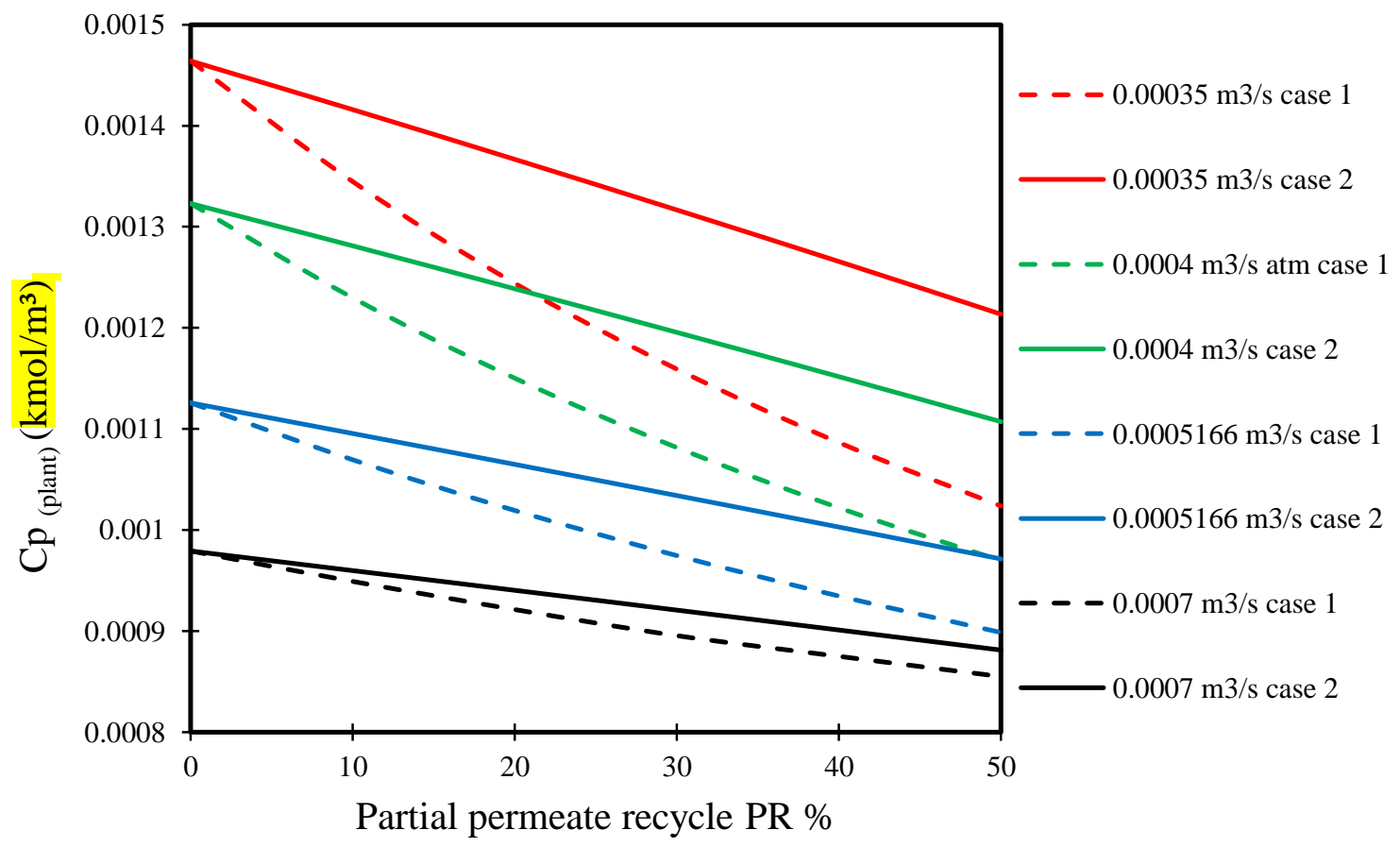

Fig. 9. The impact of plant feed flow rate on the total plant product concentration of permeate recycle design of cases 1 and 2 (plant operating conditions of case $1: 6.226 \mathrm{E}-3 \mathrm{kmol} / \mathrm{m}^{3}, 15 \mathrm{~atm}, 31^{\circ} \mathrm{C}$ and variable feed flow rate and plant operating parameters of case $2: 6.226 \mathrm{E}-3 \mathrm{kmol} / \mathrm{m}^{3}, 15 \mathrm{~atm}, 31^{\circ} \mathrm{C}$ and variable feed flow rate) 
Table 3. The simulation results of case 3 on the plant performance of cases 1 and 2 of permeate recycle design

\begin{tabular}{|c|c|c|c|c|c|c|c|c|c|c|c|}
\hline \multirow[b]{2}{*}{$\begin{array}{c}\text { Tested } \\
\text { operating } \\
\text { parameter }\end{array}$} & \multirow[b]{2}{*}{$\begin{array}{l}0 \\
\tilde{U} \\
\tilde{U}\end{array}$} & \multirow[b]{2}{*}{ 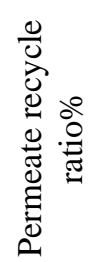 } & \multicolumn{9}{|c|}{ Tested variables } \\
\hline & & & 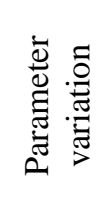 & 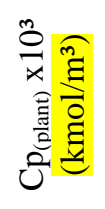 & 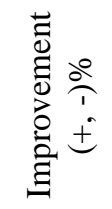 & 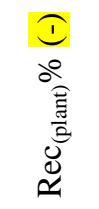 & 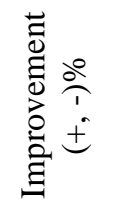 & 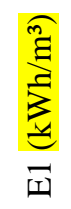 & 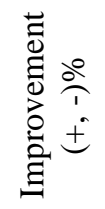 & 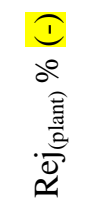 & 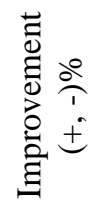 \\
\hline \multirow{6}{*}{$\begin{array}{l}\text { Flow rate } \\
(3.5 \mathrm{E}-4- \\
\left.7 \mathrm{E}-4 \mathrm{~m}^{3} / \mathrm{s}\right)\end{array}$} & Base & 0 & $3.5 \mathrm{E}-4$ & 1.46 & -- & 70.18 & -- & 0.75 & -- & 76.48 & -- \\
\hline & 1 & 50 & $3.5 \mathrm{E}-4$ & 1.02 & +30.07 & 55.17 & -21.37 & 0.95 & -27.19 & 79.48 & +3.91 \\
\hline & 2 & 50 & $3.5 \mathrm{E}-4$ & 1.21 & +17.11 & 74.23 & +5.76 & 0.71 & +5.45 & 73.35 & -4.08 \\
\hline & Base & 0 & $7 \mathrm{E}-4$ & 0.979 & -- & 32.84 & -- & 1.60 & -- & 84.27 & -- \\
\hline & 1 & 50 & $7 \mathrm{E}-4$ & 0.855 & +12.66 & 26.79 & -18.41 & 1.96 & -22.57 & 84.41 & +0.16 \\
\hline & 2 & 50 & $7 \mathrm{E}-4$ & 0.881 & +10.01 & 33.67 & +2.51 & 1.56 & +2.45 & 83.57 & -0.82 \\
\hline
\end{tabular}

\section{Conclusions}

The evaluation of the multi-stage RO process performance considering the chlorophenol removal from wastewater with and without permeate recycle schemes of constant and variable plant feed flow rate is comprehensively addressed in this research. The performance of the process is explored by investigating four indicators including; the final chlorophenol concentration of the product, total recovery rate, rejection parameter and energy consumption. The permeate recycling scheme has a significant impact on the overall plant performance compared to other schemes of recycling retentate and permeate-retentate streams. Specifically, the permeate recycle scheme observes the following:

1. The design of $50 \%$ permeate recycle of case 1 of constant external plant feed flow rate has the highest improvement in the final chlorophenol concentration of the product in a range of $10-30 \%$ based on the operating plant conditions.

2. The highest reduction in the final chlorophenol concentration of the product of case 1 of constant external plant feed flow rate is achieved at operating conditions of high feed temperature, pressure, and low feed flow rate.

3. Implementing the design of case 1 of constant external plant feed flow rate has a penalty of lowering the total recovery rate in a range of $17-28 \%$ and increasing the requirements of energy consumption in a range of $21-40 \%$ in terms of the considered variation of the plant operating parameters. 
4. The variation of operating parameters of plant feed temperature and pressure, flow rate and concentration can impose contradict impacts to the whole performance.

5. The $50 \%$ permeate recycle design of case 2 of variable external plant feed flow rate has a small influence in the recovery rate and energy consumption.

6. Both cases 1 and 2 of $50 \%$ permeate recycle schemes have inconsiderable impact on the overall chlorophenol rejection.

7. The current results suggest that it is important to implement an optimisation study for permeate recycle design to target the proper recycled ratio that attains the lowest product concentration of chlorophenol at lowest energy consumption.

\section{Nomenclature}

$A$ : Effective area of the membrane $\left(\mathrm{m}^{2}\right)$

$A_{w(T)}:$ Solvent transport coefficient at any temperature (m/atm s)

$A_{w\left(T_{\text {ref }}\right)}:$ Solvent transport coefficient at reference temperature (m/atm s)

$b:$ Feed and permeate channels friction parameter $\left(\mathrm{atm} \mathrm{s} / \mathrm{m}^{4}\right)$

$B_{S(T)}:$ Solute transport coefficient at any temperature $(\mathrm{m} / \mathrm{s})$

$B_{S\left(T_{r e f}\right)}:$ Solute transport coefficient at reference temperature $(\mathrm{m} / \mathrm{s})$

$C_{b}$ : The bulk feed solute concentrations at the feed channel $\left(\mathrm{kmol} / \mathrm{m}^{3}\right)$

$C_{f}$ : The inlet feed solute concentrations at the feed channel $\left(\mathrm{kmol} / \mathrm{m}^{3}\right)$

$C_{f(\text { mixer })(\mathrm{in})}:$ The inlet feed concentration of the mixer $\left(\mathrm{kmol} / \mathrm{m}^{3}\right)$

$C_{f(\text { mixer)(out) }}$ : The outlet feed concentration of the mixer $\left(\mathrm{kmol} / \mathrm{m}^{3}\right)$

$C_{f(\text { plant })}:$ The feed concentration of the plant $\left(\mathrm{kmol} / \mathrm{m}^{3}\right)$

$C_{f(\text { splitter }(\text { in })}:$ The inlet feed concentration of the splitter $\left(\mathrm{kmol} / \mathrm{m}^{3}\right)$

$C_{f(\text { splitter)(out) }}:$ The outlet feed concentration of the splitter $\left(\mathrm{kmol} / \mathrm{m}^{3}\right)$

$C_{m}$ : The dimensionless solute concentration (dimensionless)

$C_{p}$ : The permeate solute concentration at the permeate channel $\left(\mathrm{kmol} / \mathrm{m}^{3}\right)$

$C_{r}$ : The retentate concentration of a membrane module $\left(\mathrm{kmol} / \mathrm{m}^{3}\right)$

$C_{r(\text { plant })}:$ The retentate concentration of the plant $\left(\mathrm{kmol} / \mathrm{m}^{3}\right)$

$C_{w}$ : The solute concentration on the membrane surface at the feed channel $\left(\mathrm{kmol} / \mathrm{m}^{3}\right)$ 
$D_{b}$ : The solute diffusion coefficient of feed at the feed channel $\left(\mathrm{m}^{2} / \mathrm{s}\right)$

$D_{p}$ : The solute diffusion coefficient of feed at the permeate channel $\left(\mathrm{m}^{2} / \mathrm{s}\right)$

$d e_{b}$ : The equivalent diameters of the feed channel (m)

$d e_{p}$ : The equivalent diameters of the permeate channel (m)

$E 1$ : The total energy consumption of the whole plant $\left(\mathrm{kW} \mathrm{h} / \mathrm{m}^{3}\right)$

$J_{s}$ : The solute molar flux through the membrane $\left(\mathrm{kmol} / \mathrm{m}^{2} \mathrm{~s}\right)$

$J_{w}:$ The permeate flux $(\mathrm{m} / \mathrm{s})$

$k:$ The mass transfer coefficient at the feed channel $(\mathrm{m} / \mathrm{s})$

$L:$ The length of the membrane $(\mathrm{m})$

$m_{f}$ : Parameter in Eqs. (10) and (11) of Table A.1 of Appendix A

$n:$ Number of stages (dimensionless)

$P_{f(i n)}:$ The inlet feed pressure of a membrane module (atm)

$P_{f(\text { in) }(\text { plant })}:$ The inlet feed pressure of the plant (atm)

$P_{f(o u t)}:$ The outlet feed pressure of a membrane module (atm)

$P_{f(\text { out })(\text { plant })}:$ The retentate pressure of the plant (atm)

$P_{p}$ : The permeate channel pressure of a membrane module (atm)

$\Delta P_{f(i n)}:$ The feed and permetate pressure difference at the inlet edge of a membrane module (atm)

$\Delta P_{f(o u t)}$ : The feed and permetate pressure difference at the outlet edge of a membrane module (atm)

$P R:$ Partial recycle of stream $(\%)$

$P V:$ Pressure vessel (dimensionless)

$Q_{b}$ : The bulk feed flow rate at the feed channel of a membrane module $\left(\mathrm{m}^{3} / \mathrm{s}\right)$

$Q_{f}$ : The inlet feed flow rate at the feed channel of a membrane module $\left(\mathrm{m}^{3} / \mathrm{s}\right)$

$Q_{f(\text { plant })}:$ The inlet feed flow rate of the plant ( $\left.\mathrm{m}^{3} / \mathrm{s}\right)$

$Q_{p}$ : The permeate flow rate at the permeate channel of a membrane module $\left(\mathrm{m}^{3} / \mathrm{s}\right)$

$Q_{p(\text { Plant })}:$ The permeate flow rate of the plant ( $\left.\mathrm{m}^{3} / \mathrm{s}\right)$

$Q_{p(s)}$ : The permeate flow rate of the specific stage $\left(\mathrm{m}^{3} / \mathrm{s}\right)$

$Q_{r}$ : The retentate flow rate at the feed channel of a membrane module $\left(\mathrm{m}^{3} / \mathrm{s}\right)$ 
$Q_{r(\text { plant })}:$ The retentate flow rate of the plant $\left(\mathrm{m}^{3} / \mathrm{s}\right)$

$R$ : The gas law constant $\left(\mathrm{R}=0.082 \mathrm{~atm} \mathrm{~m}^{3} / \mathrm{K} \mathrm{kmol}\right)$

$R e_{b}$ : The Reynolds number at the feed channel (dimensionless)

$R e c$ : Total permeate recovery of a membrane module (dimensionless)

$\operatorname{Rec}_{(\text {plant })}$ : The total recovery rate of the plant (dimensionless)

$R e j:$ The solute rejection coefficient of a membrane module (dimensionless)

$R e j_{(\text {plant })}$ : The total solute rejection coefficient of the plant (dimensionless)

$R e_{p}$ : The Reynold number at the permeate channel (dimensionless)

$s:$ Stage (dimensionless)

$T:$ The feed temperature of a membrane module $\left({ }^{\circ} \mathrm{C}\right)$

$T_{(\text {in)(plant })}:$ The inlet feed temperature of the plant $\left({ }^{\circ} \mathrm{C}\right)$

$T_{(\text {out })(\text { plant })}:$ The retentate temperature of the plant $\left({ }^{\circ} \mathrm{C}\right)$

$T_{r e f}:$ The reference temperature $\left({ }^{\circ} \mathrm{C}\right)$

$t_{f}:$ Height of feed channel (m)

$t_{p}:$ Height of permeate channel $(\mathrm{m})$

$U_{b}$ : The bulk feed velocity at the feed channel of a membrane module $(\mathrm{m} / \mathrm{s})$

$W$ : The membrane width (m)

\section{Greek letters}

$\mu_{b}$ : The Feed viscosity at the feed channel of a membrane module $(\mathrm{kg} / \mathrm{m} \mathrm{s})$

$\mu_{p}$ : The permeate viscosity at the permeate channel of a membrane module $(\mathrm{kg} / \mathrm{m} \mathrm{s})$

$\rho_{b}$ : The feed density at the feed channel of a membrane module $\left(\mathrm{kg} / \mathrm{m}^{3}\right)$

$\rho_{p}$ : The permeate density at the permeate channel of a membrane module $\left(\mathrm{kg} / \mathrm{m}^{3}\right)$

$\rho_{w}:$ Molal density of water $\left(55.56 \mathrm{kmol} / \mathrm{m}^{3}\right)$

$\theta$ : Parameter in Eq. (24) of Table A.1 of Appendix A

$\varepsilon_{\text {pump }}:$ Pump efficiency (dimensionless)

\section{References}

Al-Bastaki N., Abbas A., 2003. Permeate recycle to improve the performance of a spiral-wound RO plant. Desalination, 158(1-3), 119-126. 
Al-Obaidi M.A., Mujtaba I.M., 2016. Steady state and dynamic modeling of spiral wound wastewater reverse osmosis process. Computers and Chemical Engineering, 90, 278-299.

Al-Obaidi M.A., Kara-Zaïtri C., Mujtaba I.M., 2017a. Wastewater treatment by spiral wound reverse osmosis: Development and validation of a two dimensional process model. Journal of Cleaner Production, 140, 1429-1443.

Al-Obaidi M.A., Li J-P., Kara-Zaïtri C., Mujtaba I.M., 2017b. Optimisation of reverse osmosis based wastewater treatment system for the removal of chlorophenol using genetic algorithms. Chemical Engineering Journal, 316, 91-100.

Al-Obaidi M.A., Kara-Zaïtri C., Mujtaba I.M., 2017c. Modeling of a spiral-wound reverse osmosis process and parameter estimation. Desalination and Water Treatment, 69, 93-101. doi:10.5004/dwt.2017.0641.

Al-Obaidi M.A., Kara-Zaïtri C., Mujtaba I.M., 2017. Optimisation of membrane design parameters of a spiral-wound reverse osmosis module for high rejection of dimethylphenol from wastewater at low energy consumption, In Computer Aided Process Engineering-40, Espuna et al. (editors), 2713-2718. http://dx.doi.org/10.1016/B978-0-444-63965-3.50454-2

Al-Obaidi M.A., Kara-Zaïtri C., Mujtaba I.M., 2018. Simulation and sensitivity analysis of spiral wound reverse osmosis process for the removal of dimethylphenol from wastewater using 2-D dynamic model. Journal of Cleaner Production, 193, 140-157.

Busca G., Berardinelli S., Resini C., Arrighi L., 2008. Technologies for the removal of phenol from fluid streams: A short review of recent developments. Journal of Hazardous Materials, $160,265-288$.

Gami A.A. Shukor M.Y., Abdul Khalil K., Dahalan F.A., Khalid A., Ahmad S.A. 2014. Phenol and its toxicity. Journal of Environmental Microbiology and Toxicology, 2(1), 11-24.

Gómez J., León G., Hidalgo A., Gómez M., Murcia M., Griñán G., 2009. Application of reverse osmosis to remove aniline from wastewater. Desalination, 245, 687-693. 
Gu B., Xu X.Y., Adjiman C.S., 2017. A predictive model for spiral wound reverse osmosis membrane modules: The effect of winding geometry and accurate geometric details. Computers and Chemical Engineering, 96, 248-265.

Hill G.A., Robinson C.W., 1975. Substrate inhibition kinetics: Phenol degradation by Pseudomonas putida. Biotechnology and Bioengineering, 17(11), 1599-1615.

Jiang H., Fang Y., Fu Y., Guo Q-X., 2003. Studies on the extraction of phenol in wastewater. Journal of Hazardous Materials, B101, 179-190.

Jiang A., Ding Q., Wang J., Jiangzhou S., Cheng W., Xing C., 2014. Mathematical modeling and simulation of SWRO process based on simultaneous method. Journal of Applied Mathematics, 2014.

Koroneos C., Dompros A., Roumbas G., 2007. Renewable energy driven desalination systems modelling. Journal of Cleaner Production, 15, 449-464.

Lee C., Chen Y., Wang G., 2010. A dynamic simulation model of reverse osmosis desalination systems. The 5th International Symposium on Design, Operation and Control of Chemical Processes, PSE Asia, Singapore

Mohammed A.E., Jarullah A.T., Gheni S.A., Mujtaba I.M., 2016. Optimal design and operation of an industrial three phase reactor for the oxidation of phenol. Computers and Chemical Engineering, 94, 257-271.

Mohammed A.E., Jarullah A.T., Gheni S.A., Mujtaba I.M., 2017. Significant cost and energy savings opportunities in industrial three phase reactor for phenol oxidation. Computers and Chemical Engineering, 104, 201-210.

Pinto R.T.P., Lintomen L., Luz Jr. L.F.L., Wolf-Maciel M.R., 2005. Strategies for recovering phenol from wastewater: thermodynamic evaluation and environmental concerns. Fluid Phase Equilibria, 228-229, 447-457.

Process System Enterprise Ltd. 2001. gPROMS Introductory User Guide. London: Process System Enterprise Ltd. 
Sarkar P., Goswami D., Prabhakar S., Tewari P.K., 2008. Optimized design of a reverse osmosis system with a recycle. Desalination, 230, 128-139.

Srinivasan G., Sundaramoorthy S., Murthy D.V.R., 2009. Separation of dimethyl phenol using a spiral-wound RO membrane-Experimental and parameter estimation studies. Desalination, 243, 170-181.

Srinivasan G., Sundaramoorthy S., Murthy D.V.R., 2010. Spiral wound reverse osmosis membranes for the recovery of phenol compounds-Experimental and parameter estimation studies. American Journal of Engineering and Applied Sciences, 3(1), 31-36.

Srinivasan G., Sundaramoorthy S., Murthy D.V.R., 2011. Validation of an analytical model for spiral wound reverse osmosis membrane module using experimental data on the removal of dimethylphenol. Desalination, 281, 199-208.

Sundaramoorthy S., Srinivasan G., Murthy D.V.R., 2011a. An analytical model for spiral wound reverse osmosis membrane modules: Part II - Experimental validation. Desalination, 277(1-3), 257-264.

Sundaramoorthy S., Srinivasan G., Murthy D. V. R., 2011b. An analytical model for spiral wound reverse osmosis membrane modules: Part I - Model development and parameter estimation. Desalination, 280(1-3), 403-411. 


\section{Appendix A}

Table A.1. Mathematical modelling of a single spiral wound RO system (Al-Obaidi et al., 2017d)

\begin{tabular}{|c|c|c|}
\hline Model Equations & Specifications & $\begin{array}{l}\text { Eq. } \\
\text { no. }\end{array}$ \\
\hline$J_{w}=A_{w(T)}\left[\left(\frac{\left(P_{f(\text { in })}+P_{f(\text { out })}\right)}{2}-P_{p}\right)-\left(R(T+273.15)\left(C_{w}-C_{p}\right)\right)\right]$ & The permeate flux & 1 \\
\hline$J_{s}=B_{s(T)}\left(C_{w}-C_{p}\right)$ & The solute flux & 2 \\
\hline$\frac{\left(C_{w}-C_{p}\right)}{\left(C_{b}-C_{p}\right)}=\exp \left(\frac{J_{w}}{k}\right)$ & The wall solute concentration & 3 \\
\hline$k=\frac{147.4 D_{b} R e_{b}^{0.13} R e_{p}^{0.739} C_{m}^{0.135}}{2 t_{f}}$ & $\begin{array}{l}\text { The mass transfer coefficient } \\
\text { (Sundaramoorthy et al., 2011b) }\end{array}$ & 4 \\
\hline$C_{m}=\frac{C_{b}}{\rho_{w}}$ & $\begin{array}{l}\text { The dimensionless solute } \\
\text { concentration }\end{array}$ & 5 \\
\hline$D_{b}=6.725 E-6 \exp \left\{0.1546 E-3\left(C_{f} x 18.0125\right)-\frac{2513}{(T+273.15)}\right\}$ & $\begin{array}{l}\text { The diffusivity parameter at the } \\
\text { feed channel (Koroneos, 2007) }\end{array}$ & 6 \\
\hline$D_{p}=6.725 E-6 \exp \left\{0.1546 E-3\left(C_{p} x 18.0125\right)-\frac{2513}{(T+273.15)}\right\}$ & $\begin{array}{l}\text { The diffusivity parameter at the } \\
\text { permeate channel }\end{array}$ & 7 \\
\hline$\left.\mu_{b}=1.234 E-6 \exp \left\{0.0212 C_{f} x 18.0153\right)+\frac{1965}{(T+273.15)}\right\}$ & $\begin{array}{l}\text { The dynamic viscosity at the feed } \\
\text { channel }\end{array}$ & 8 \\
\hline$\left.\mu_{p}=1.234 E-6 \exp \left\{0.0212 C_{p} x 18.0153\right)+\frac{1965}{(T+273.15)}\right\}$ & $\begin{array}{l}\text { The dynamic viscosity at the } \\
\text { permeate channel }\end{array}$ & 9 \\
\hline$\rho_{b}=498.4 m_{f}+\sqrt{\left[248400 m_{f}^{2}+752.4 m_{f} C_{f} x 18.01253\right]}$ & The feed density & 10 \\
\hline$\rho_{p}=498.4 m_{f}+\sqrt{\left[248400 m_{f}^{2}+752.4 m_{f} C_{p} x 18.01253\right]}$ & The permeate density & 11 \\
\hline$m_{f}=1.0069-2.757 E-4(T)$ & Parameter in Eqs. (10) and (11) & 12 \\
\hline$R e_{b}=\frac{\rho_{b} d e_{b} Q_{b}}{t_{f} W \mu_{b}}$ & $\begin{array}{l}\text { The Reynolds number at the feed } \\
\text { channel }\end{array}$ & 13 \\
\hline$R e_{p}=\frac{\rho_{p} d e_{p} J_{w}}{\mu_{p}}$ & $\begin{array}{l}\text { The Reynolds number at the } \\
\text { permeate channel }\end{array}$ & 14 \\
\hline$d e_{b}=2 t_{f} \quad d e_{p}=2 t_{p}$ & $\begin{array}{l}\text { The equivalent diameters of the } \\
\text { feed and permeate channels }\end{array}$ & 15 \\
\hline$U_{b}=\frac{Q_{b}}{W t_{f}}$ & The bulk feed velocity & 16 \\
\hline$Q_{b}=\frac{Q_{f}+Q_{r}}{2}$ & The bulk feed flow rate & 17 \\
\hline$C_{b}=\frac{C_{f}+C_{r}}{2}$ & The bulk concentration & 18 \\
\hline$C_{p}=\frac{J_{s}}{J_{w}+J_{s}}$ & The permeate solute concentration & 19 \\
\hline$Q_{f}=Q_{r}+Q_{p}$ & The retentate flow rate & 20 \\
\hline$Q_{f} C_{f}=Q_{r} C_{r}+Q_{p} C_{p}$ & The retentate concentration & 21 \\
\hline$Q_{p}=J_{w} A$ & The total permeated flow rate & 22 \\
\hline 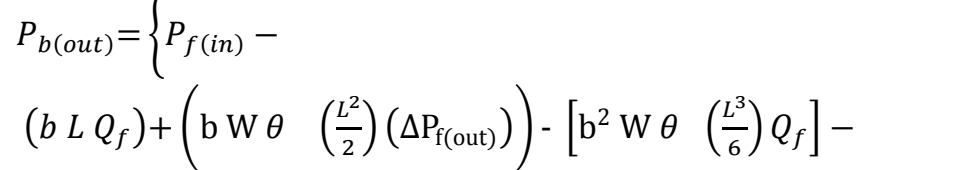 & $\begin{array}{l}\text { The retentate pressure (Al-Obaidi et } \\
\text { al., 2017b) }\end{array}$ & 23 \\
\hline
\end{tabular}


$\left.\left[b^{2} W \theta\left(\frac{W \theta}{b}\right)^{0.5}\left(\frac{L^{3}}{6}\right)\left(\Delta P_{f(\text { out })}-\Delta P_{f(\text { in })}\right)\right]\right\}$

Table A.1. Mathematical modelling of a single spiral-wound RO system (Al-Obaidi et al., 2017d) (Continued)

\begin{tabular}{|c|c|c|}
\hline Model Equations & Specifications & $\begin{array}{l}\text { Eq. } \\
\text { no. }\end{array}$ \\
\hline$\theta=\frac{A_{w(T)} B_{S(T)}}{B_{S(T)}+R(T+273.15) A_{w(T)} C_{p}}$ & Parameter in Eq. (23) & 24 \\
\hline$\Delta P_{f(i n)}=P_{b(i n)}-P_{p}$ & $\begin{array}{l}\text { The pressure difference at the inlet } \\
\text { edge }\end{array}$ & 25 \\
\hline$\Delta P_{f(\text { out })}=P_{b(\text { out })}-P_{p}$ & $\begin{array}{l}\text { The pressure difference at the outlet } \\
\text { edge }\end{array}$ & 26 \\
\hline $\operatorname{Rec}=\frac{Q_{p}}{Q_{f}} \times 100$ & The total permeate recovery & 27 \\
\hline$R e j=\frac{C_{f}-C_{p}}{C_{f}} \times 100$ & The solute rejection & 28 \\
\hline$E 1=\frac{\frac{\left(\left(P_{f(\text { in })(\text { plant })} \times 1013<J\right) Q_{f(\text { plant })}\right.}{Q_{p(\text { plant })} \varepsilon_{\text {pump }}}}{36 E 5}$ & The total plant energy consumption & 29 \\
\hline$A_{w(T+273.15)}=A_{w\left(T_{r e f}+273.15\right)} \frac{\mu_{b\left(T_{r e f}+273.15\right)}}{\mu_{b(T+273.15)}}$ & $\begin{array}{l}\text { The impact of temperature on water } \\
\text { permeability constant (Sarkar et al., } \\
\text { 2008) }\end{array}$ & 30 \\
\hline$B_{S(T+273.15)}=B_{s\left(T_{r e f}+273.15\right)} \frac{T+273.15}{T_{r e f}+273.15} \frac{\mu_{b\left(T_{r e f}+273.15\right)}}{\mu_{b(T+273.15)}}$ & $\begin{array}{l}\text { The impact of temperature on solute } \\
\text { permeability constant (Sarkar et al., } \\
\text { 2008) }\end{array}$ & 31 \\
\hline
\end{tabular}

Table A.2. Mathematical modelling of multi-stage RO system with and without partial recycle

\begin{tabular}{|c|c|c|}
\hline Model Equations & Specifications & $\begin{array}{l}\text { Eq. } \\
\text { no. }\end{array}$ \\
\hline$Q_{f(\text { plant })}=Q_{r(\text { plant })}+Q_{p(\text { plant })}$ & $\begin{array}{l}\text { Mass balance of the whole plant } \\
\text { without recycle }\end{array}$ & 32 \\
\hline$Q_{f(\text { lant })}=Q_{f(s=1)}$ & $\begin{array}{l}\text { Feed flow rate of the stage } 1 \text { without } \\
\text { recycle }\end{array}$ & 33 \\
\hline$Q_{r(\text { plant })}=Q_{r(s=n)} \quad \mathrm{n}:$ number of stages & Retentate flow rate of the plant & 34 \\
\hline$Q_{p(\text { Plant })}=\sum_{s=1}^{n} Q_{p(s)}$ & Total permeate flow rate of the plant & 35 \\
\hline$P_{f(\text { in })(\text { plant })}=P_{f(\text { in })(s=1)}$ & Feed pressure of stage 1 & 36 \\
\hline$P_{f(\text { out })(\text { plant })}=P_{f(\text { out })(s=n)}$ & Retentate pressure of the whole plant & 37 \\
\hline$T_{(\text {in })(\text { plant })}=T_{(\text {out })(\text { plant })}$ & $\begin{array}{l}\text { The assumption of constant } \\
\text { temperature }\end{array}$ & 38 \\
\hline$C_{f(\text { plant })}=C_{f(s=1)}$ & $\begin{array}{l}\text { The feed concentration of the first } \\
\text { stage }\end{array}$ & 39 \\
\hline$C_{r(\text { plant })}=C_{r(s=n)} \quad \mathrm{n}$ : number of stages & $\begin{array}{l}\text { The retentate concentration of the } \\
\text { plant }\end{array}$ & 40 \\
\hline$Q_{f(\text { plant })} C_{f(\text { plant })}=Q_{r(\text { plant })} C_{r(\text { plant })}+Q_{p(\text { lant })} C_{p(\text { plant })}$ & $\begin{array}{l}\text { Mass balance of the whole plant } \\
\text { without recycle }\end{array}$ & 41 \\
\hline$R e j_{(\text {plant })}=\frac{C_{f(\text { plant })}-C_{p(\text { plant })}}{C_{f(\text { plant })}} \times 100$ & The total rejection of the plant & 42 \\
\hline $\operatorname{Rec}_{(\text {plant })}=\frac{Q_{p(\text { plant })}}{Q_{f(\text { plant })}} \times 100$ & $\begin{array}{l}\text { The total permeate recovery of the } \\
\text { plant }\end{array}$ & 43 \\
\hline
\end{tabular}


Table A.2. Mathematical modelling of multi-stage RO system with and without partial recycle (Continued)

\begin{tabular}{|c|c|c|}
\hline Model Equations & Specifications & $\begin{array}{l}\text { Eq. } \\
\text { no. }\end{array}$ \\
\hline$C_{f(s)}=C_{r(s-1)}$ & The feed concentration of each stage & 44 \\
\hline$P_{f(\text { in })(s)}=P_{f(\text { out })(s-1)}$ & The feed pressure of each stage & 45 \\
\hline$Q_{f(s)}=\underset{n}{Q_{r(s-1)}}$ & The feed flow rate of each stage & 46 \\
\hline$Q_{r(s)}=\sum_{P V=1} Q_{r(P V)}$ & The retentate of each stage & 47 \\
\hline$Q_{p(s)}=\sum_{P V=1}^{n} Q_{p(P V)}$ & $\begin{array}{l}\text { The total permeate flow rate of each } \\
\text { stage }\end{array}$ & 48 \\
\hline$Q_{f(s)} C_{f(s)}=Q_{r(s)} C_{r(s)}+Q_{p(s)} C_{p(s)}$ & Mass balance of each stage & 49 \\
\hline $\operatorname{Rec}_{(s)}=\frac{Q_{p(s)}}{Q_{f(s)}} \times 100$ & $\begin{array}{l}\text { The total permeate recovery of each } \\
\text { stage }\end{array}$ & 50 \\
\hline$Q_{f(P V)(s)}=\frac{Q_{f(s)}}{n_{(P V)}} \quad$ n: number of pressure vessels & $\begin{array}{l}\text { The feed flow rate of each pressure } \\
\text { vessel in the stage }\end{array}$ & 51 \\
\hline$P_{f(i n)(P V)}=P_{f(i n)(s)}$ & $\begin{array}{l}\text { The feed pressure of each pressure } \\
\text { vessel }\end{array}$ & 52 \\
\hline$C_{f(P V)}=C_{f(s)}$ & $\begin{array}{l}\text { The feed concentration of each } \\
\text { pressure vessel }\end{array}$ & 53 \\
\hline$Q_{f(\text { splitter })(\text { in })}=\sum_{\text {out }=1}^{n} Q_{f(\text { splitter })(\text { out })}$ & The feed flow rate of a splitter & 54 \\
\hline$C_{f(\text { splitter })(\text { in })}=C_{f(\text { splitter })(o u t)}$ & The feed concentration of a splitter & 55 \\
\hline$P_{f(\text { splitter })(\text { in })} Q_{f(\text { splitter })(\text { in })}=P_{f(\text { splitter })(\text { out })} \sum_{\text {out }=1}^{n} Q_{f(\text { splitter })(\text { out })}$ & The feed pressure of a splitter & 56 \\
\hline$Q_{f(\text { mixer })(\text { out })}=\sum_{i n=1}^{n} Q_{f(\text { mixer })(\text { in })}$ & The feed flow rate of a mixer & 57 \\
\hline$C_{f(\text { mixer })(\text { out })} Q_{f(\text { mixer })(\text { out })}=C_{f(\text { mixer })(\text { in })} \sum_{i n=1}^{n} Q_{f(\text { mixer })(\text { in })}$ & The feed concentration of a mixer & 58 \\
\hline$P_{f(\text { mixer })(\text { out })} Q_{f(\text { mixer })(\text { out })}=P_{f(\text { mixer })(\text { in })} \sum_{i n=1}^{n} Q_{f(\text { mixer })(\text { in })}$ & The feed pressure of a mixer & 59 \\
\hline$Q_{f(\text { plant })} C_{f(\text { plant })}+P R Q_{r(\text { plant })} C_{r(\text { plant })}=Q_{f(s=1)} C_{f(s=1)}$ & $\begin{array}{l}\text { Solute balance of partial recycle of } \\
\text { retentate }\end{array}$ & 60 \\
\hline$Q_{f(\text { plant })}+P R Q_{r(\text { plant })}=Q_{f(s=1)}$ & $\begin{array}{l}\text { Mass balance of partial recycle of } \\
\text { retentate }\end{array}$ & 61 \\
\hline$Q_{f(\text { plant })} C_{f(\text { plant })}+P R Q_{p(\text { plant })} C_{p(\text { plant })}=Q_{f(s=1)} C_{f(s=1)}$ & $\begin{array}{l}\text { Solute balance of both partial recycle } \\
\text { of permeate }\end{array}$ & 62 \\
\hline$Q_{f(\text { plant })}+P R Q_{p(\text { plant })}=Q_{f(s=1)}$ & $\begin{array}{l}\text { Mass balance of partial recycle of } \\
\text { permeate }\end{array}$ & 63 \\
\hline $\begin{array}{l}Q_{f(\text { plant })} C_{f(\text { plant })}+P R Q_{r(\text { plant })} C_{r(\text { plant })}+ \\
P R Q_{p(\text { plant })} C_{p(\text { plant })}=Q_{f(s=1)} C_{f(s=1)}\end{array}$ & $\begin{array}{l}\text { Solute balance of both partial recycle } \\
\text { of retentate and permeate }\end{array}$ & 64 \\
\hline$Q_{f(\text { plant })}+P R Q_{r(\text { plant })}+P R Q_{p(\text { plant })}=Q_{f(s=1)}$ & $\begin{array}{l}\text { Mass balance of partial recycle of } \\
\text { retentate and permeate }\end{array}$ & 65 \\
\hline
\end{tabular}




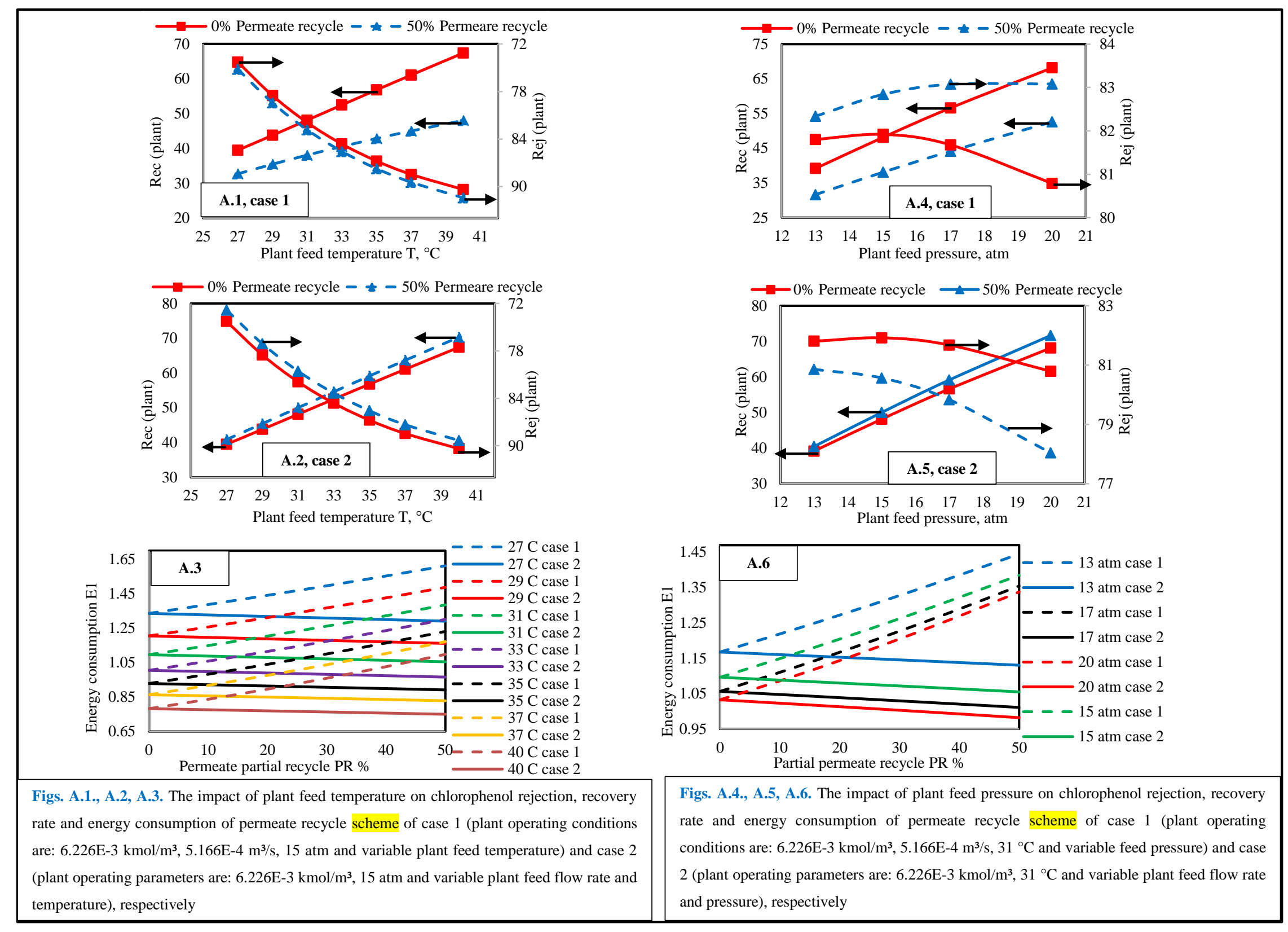




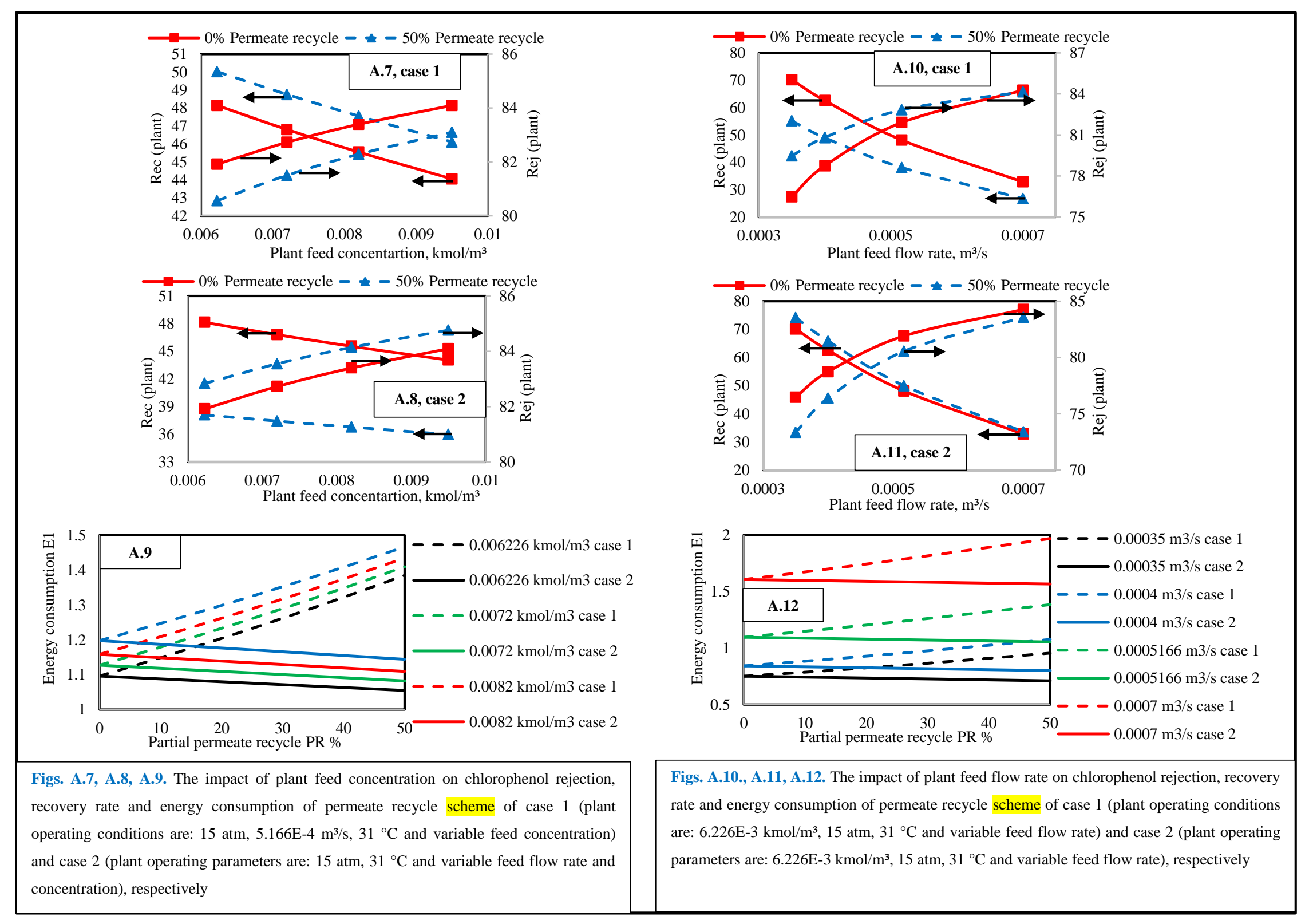


